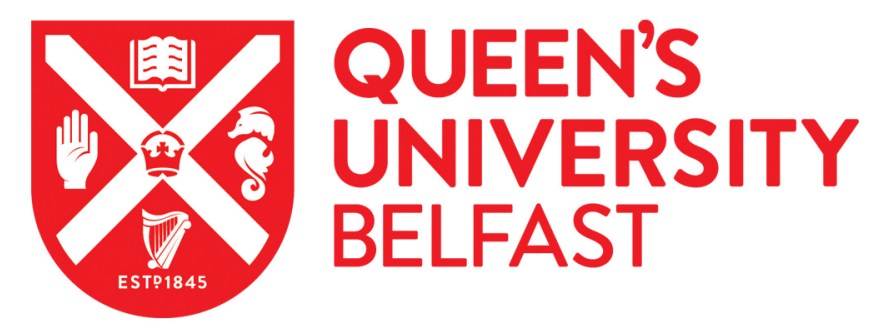

\title{
Predicting low velocity impact damage and Compression-After-Impact (CAl) behaviour of composite laminates
}

Tan, W., Falzon, B. G., Chiu, L. N. S., \& Price, M. (2015). Predicting low velocity impact damage and Compression-After-Impact (CAI) behaviour of composite laminates. Composites Part A: Applied Science and Manufacturing, 71, 212-226. https://doi.org/10.1016/j.compositesa.2015.01.025

\section{Published in:}

Composites Part A: Applied Science and Manufacturing

\section{Document Version:}

Peer reviewed version

Queen's University Belfast - Research Portal:

Link to publication record in Queen's University Belfast Research Portal

\section{Publisher rights}

Copyright 2015 Elsevier

This manuscript version is made available under a Creative Commons Attribution-NonCommercial-NoDerivs License

(https://creativecommons.org/licenses/by-nc-nd/4.0/), which permits distribution and reproduction for non-commercial purposes, provided the author and source are cited.

\section{General rights}

Copyright for the publications made accessible via the Queen's University Belfast Research Portal is retained by the author(s) and / or other copyright owners and it is a condition of accessing these publications that users recognise and abide by the legal requirements associated with these rights.

\footnotetext{
Take down policy

The Research Portal is Queen's institutional repository that provides access to Queen's research output. Every effort has been made to ensure that content in the Research Portal does not infringe any person's rights, or applicable UK laws. If you discover content in the Research Portal that you believe breaches copyright or violates any law, please contact openaccess@qub.ac.uk.
} 


\section{Accepted Manuscript}

Predicting low velocity impact damage and Compression-After-Impact (CAI) behaviour of composite laminates

Wei Tan, Brian G. Falzon, Louis N.S. Chiu, Mark Price

PII:

S1359-835X(15)00036-6

DOI: http://dx.doi.org/10.1016/j.compositesa.2015.01.025

Reference: JCOMA 3838

To appear in:

Composites: Part A

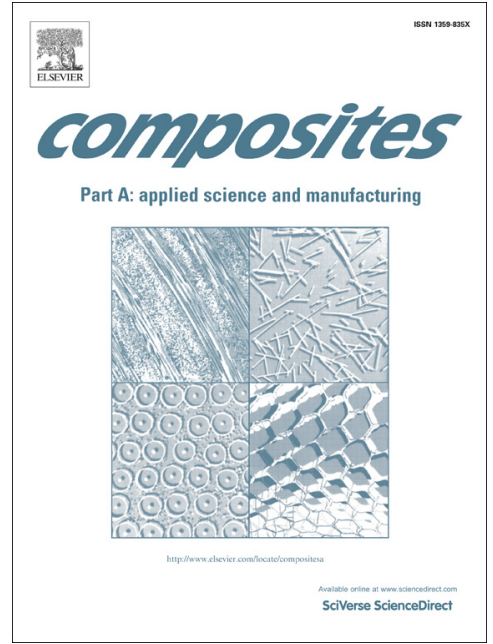

Received Date: $\quad 16$ April 2014

Revised Date: $\quad 19$ January 2015

Accepted Date: $\quad 20$ January 2015

Please cite this article as: Tan, W., Falzon, B.G., Chiu, L.N.S., Price, M., Predicting low velocity impact damage and Compression-After-Impact (CAI) behaviour of composite laminates, Composites: Part A (2015), doi: http:// dx.doi.org/10.1016/j.compositesa.2015.01.025

This is a PDF file of an unedited manuscript that has been accepted for publication. As a service to our customers we are providing this early version of the manuscript. The manuscript will undergo copyediting, typesetting, and review of the resulting proof before it is published in its final form. Please note that during the production process errors may be discovered which could affect the content, and all legal disclaimers that apply to the journal pertain. 


\section{Predicting low velocity impact damage and Compression-After-Impact (CAI) behaviour of composite}

\section{laminates}

Wei Tan ${ }^{1}$, Brian G. Falzon ${ }^{1 *}$, Louis N. S. Chiu², Mark Price ${ }^{1}$

1 School of Mechanical and Aerospace Engineering, Queen's University Belfast, Ashby Building, Belfast, BT9 $5 \mathrm{AH}, \mathrm{UK}$

2 Department of Mechanical and Aerospace Engineering, Monash University, Building 31, Clayton, VIC 3800,

Australia

* b.falzon@qub.ac.uk (B.G. Falzon)

\section{Abstract}

Low-velocity impact damage can drastically reduce the residual strength of a composite structure even when the damage is barely visible. The ability to computationally predict the extent of damage and Compression-After-Impact (CAI) strength of a composite structure can potentially lead to the exploration of a larger design space without incurring significant time and cost penalties. A high-fidelity three-dimensional composite damage model, to predict both low-velocity impact damage and CAI strength of composite laminates, has been developed and implemented as a user material subroutine in the commercial finite element package, ABAQUS/Explicit. The intralaminar damage model component accounts for physicallybased tensile and compressive failure mechanisms, of the fibres and matrix, when subjected to a threedimensional stress state. Cohesive behaviour was employed to model the interlaminar failure between plies with a bi-linear traction-separation law for capturing damage onset and subsequent damage evolution. The virtual tests set up in ABAQUS/Explicit were executed in three steps, one to capture the impact damage, the second to stabilize the specimen by imposing new boundary conditions required for compression testing and the third to predict the CAI strength. The observed intralaminar damage features, delamination damage area as well as residual strength are discussed. It is shown that the predicted results for impact damage and CAI

\section{Page 1 of 53}


strength correlated well with experimental testing without the need of model calibration which is often required with other damage models.

Keywords: B. Impact behaviour, B. Strength, C. Damage mechanics, C. Computational modelling, C. Numerical analysis, C. Finite element analysis (FEA)

\section{Introduction}

Composite materials are increasingly being used in aerospace structures due to their high specific stiffness and strength, corrosion resistance and fatigue performance. Nevertheless, the susceptibility to damage from low-velocity impact events (e.g. accidental damage incurred during routine maintenance) is a major concern. When subjected to impact loading, a composite structure is degraded through various failure mechanisms involving the interaction of matrix cracking, fibre pullout/breakage and delamination. Even with barely visible impact damage (BVID), strength can be significantly reduced. The accurate assessment of the influence of impact damage currently requires extensive experimental testing to meet certification requirements, which is costly and time-consuming. It is therefore essential that a reliable computation tool is developed to support the certification process for the accurate prediction of impact damage and the corresponding residual strength.

Various composite damage models have been presented in the literature in recent years, focusing on the application of continuum damage mechanics (CDM) as proposed by Kachanov [1] and further developed by Lemaitre and Chaboche [2]. Most of these models are based on capturing the behaviour of unidirectional pre-impregnated composite plies, reflecting their prevalent use in high-performance applications. Accurately capturing transverse compressive matrix and longitudinal (fibre-dominated) damage are considered essential features of a reliable damage model. A number of the computational damage models reported, have adopted Puck and Shurmann's [3] phenomenological methodology for determining the initiation of matrix fracture. Contributions to the characterisation of longitudinal compressive failure were reported by Pinho et al. $[4,5]$. Page 2 of 53 
Donadon et al.[6] and Falzon et al. [7-9] presented a three dimensional (3D) CDM-based material model to investigate the progressive intralaminar degradation of composite laminates with non-linear shear behaviour, ply friction and damage irreversibility taken into account. This model was combined with cohesive elements to capture interlaminar damage. Raimondo et al. [10] proposed a similar intralaminar model where the matrix crack orientation, within each finite element, was permitted to assume an orientation parallel to the ply interfaces to approximate delamination and consequently, interface elements were not used to capture delamination. This implementation also made use of a crack density parameter instead of a characteristic length measure for mesh objectivity which, in the absence of appropriate reliable experimental data, is effectively a calibration parameter. More recently, Bouvet et al. [11] andHongkarnjanakul et al. [12] captured intralaminar matrix cracking in a 3D finite element mesh using cohesive interface elements through the thickness of each ply, which in turn was modelled with a single layer of 3D elements. Cohesive elements were also used to capture delamination.

A number of researchers have published experimental results on CAl of composite laminates. Uda et al. [13] investigated the failure mechanisms of impact-damaged UT500/Epoxy and AS4/PEEK CFRP laminates subjected to compression fatigue. Ghelli and Minak [14] conducted CAI tests on thin laminates where interactions between the extent of impact damage and buckling mode shape were shown to influence the overall strength of the specimens. CAI tests were also performed to investigate the residual strength of a composite laminate with a cork thermal shield [15] , assess the effectivenss of self-healing composites in recovering CAI strength [16] and compare the influence of matrix toughness using thermoset and thermoplastic resins on CAI behaviour [17].

Compared to the research effort associated with experimental tests, fewer studies have been reported on both impact and CAI simulation. Davies et al. [18] investigated the CAI strength of composite sandwich panels where the honeycomb core was simulated using an elasto-plastic material formulation in compression and shear. González et al. [19] proposed a 3D finite element model with interlaminar and intralaminar damage using a rigorous thermodynamic framework, for drop-weight impact and CAI test simulations, and studied the Page 3 of 53 
effect of different stacking sequences. Rivallant et al. [20] also presented a finite element model focussing on the fibre failure and delamination to simulate both impact and residual strength tests, and achieved good correlation between experimental and numerical results.

The work presented in this paper exploits improvements made to the composite damage model by Falzon et al. [7-9, 21], which include an improved non-linear shear response and a unified matrix-dominated damage initiation and mixed-mode intralaminar damage progression, to simulate both impact and compression after impact. The predictive capabilities of the model are confirmed by validating with experimental results obtained from the literature without the need for calibrating any of the published experimentally-determined material parameters from established testing laboratories.

\section{Composite damage model}

The failure modes exhibited by laminated composites can be broadly classified into intralaminar (matrix cracks and fibre pullout/breakage) and interlaminar (delamination) damage as shown in Fig. 1.

\section{INSERT: Fig. 1. Damage modes in laminated composites}

The effective stresses are defined as stresses transmitted across the intact part of the cross-section in a Representative Volume Element (RVE). The damage tensor is a function of three monotonically increasing damage variables, bound by 0 (no damage) and 1 (complete failure), each relating to a form of damage mode under a different loading state; (i) $d_{11}^{T}$ refers to tensile damage in the fibre direction, (ii) $d_{11}^{C}$ refers to compressive damage in the fibre direction and (iii) $d_{\text {mat }}$ refers to matrix cracking due to a combination of transverse tension/compression and shear loading, which is a unified matrix damage mechanism and replaces the previous model presented in [7].

\section{Page 4 of 53}


The components of the effective stress tensor, $\sigma$, and true stress tensor, $\sigma$, can be linked by the damage tensor, $\mathbf{D}$, undamaged material elasticity tensor $\mathbf{C}$ and the strain tensor $\varepsilon$,

$$
\sigma=\mathbf{D} \sigma=\mathbf{D C} \varepsilon
$$

assuming strain equivalence, where

$$
\mathbf{C}=\left[\begin{array}{ccccc}
\frac{1-v_{23} v_{32}}{E_{22} E_{33} \Psi} & \frac{v_{21}+v_{31} v_{23}}{E_{22} E_{33} \Psi} & \frac{v_{31}+v_{21} v_{32}}{E_{22} E_{33} \Psi} & & \\
\frac{v_{12}+v_{13} v_{32}}{E_{11} E_{33} \Psi} & \frac{1-v_{31} v_{13}}{E_{11} E_{33} \Psi} & \frac{v_{32}+v_{31} v_{12}}{E_{11} E_{33} \Psi} & & \\
\frac{v_{13}+v_{12} v_{23}}{E_{22} E_{11} \Psi} & \frac{v_{23}+v_{13} v_{21}}{E_{22} E_{11} \Psi} & \frac{1-v_{12} v_{21}}{E_{22} E_{11} \Psi} & & \\
& & & G_{12} & \\
& & & G_{23} & \\
& & & & G_{13}
\end{array}\right]
$$

and $\quad \Psi=\frac{1-v_{12} v_{21}-v_{23} v_{32}-v_{31} v_{13}-2 v_{12} v_{23} v_{31}}{E_{11} E_{22} E_{33}}$

In order to maintain a positive definite elasticity tensor, $\mathbf{C}$, the Poisson's ratios must also be degraded when damage has initiated according to Eqn. (3). This approach is consistent with the experimentally observed Poisson's ratio degradation that accompanies the progression of damage in composite materials [22].

$$
\frac{v_{i j, d}}{E_{i i, d}}=\frac{v_{i j}\left(1-d_{i i}\right)}{E_{i i}\left(1-d_{i i}\right)}=\frac{v_{j i}\left(1-d_{j j}\right)}{E_{j j}\left(1-d_{j j}\right)}=\frac{v_{j i, d}}{E_{j j, d}}, i, j=1,2,3
$$

To account for irreversibility, the damage variable as a function of analysis time, $t$, defined as

$$
\left\{\begin{array}{c}
d_{i i}(t+t)=\max \left\{0, \min \left\{1, d_{i i}(t+t)\right\}\right\} \\
d_{i i}(t+t) \geq d_{i i}(t)
\end{array}, i=1,2,3 .\right.
$$




\subsection{Intralaminar damage model}

\subsubsection{Fibre-dominated failure modes}

A bilinear law (Fig. 2) was used, for simplicity, to model the material response in the fibre direction where damage is characterised by fibre pullout, fibre-matrix debonding and fibre breakage. The point of damage initiation was found by comparing the strain to the longitudinal failure initiation strain. Damage initiation functions were defined for both tensile $F_{11}^{T}$ and compressive $F_{11}^{C}$ loading,

$$
\begin{aligned}
& F_{11}^{T}\left(\varepsilon_{11}\right)=\left(\frac{\varepsilon_{11}}{\varepsilon_{11}^{O T}}\right)^{2} \geq 1 \\
& F_{11}^{C}\left(\varepsilon_{11}\right)=\left(\frac{\varepsilon_{11}}{\varepsilon_{11}^{O C}}\right)^{2} \geq 1,
\end{aligned}
$$

where the failure initiation strains ( $\varepsilon_{11}^{O T}$ and $\varepsilon_{11}^{O C}$ for tension and compression, respectively) were determined by the strengths in the respective directions, i.e. $\varepsilon_{11}^{O T}=X^{T} / E_{11}^{0}$ etc. When the initiation function reaches unity, damage begins to grow and the transmitted stress is gradually reduced to zero,

$$
\sigma_{11}^{T(C)}=\left(1-d_{11}^{T(C)}\right) \tilde{\sigma}_{11}^{T(C)}
$$

INSERT: Fig. 2. Bilinear law (shaded area is volumetric strain energy density $g_{11}^{T(C)}$ )

The area under the traction-separation curve, is the volumetric strain energy density and the damage parameter associated with a reduction in secant stiffness, under loading in the fibre direction, is given by 


$$
d_{11}^{T(C)}\left(\varepsilon_{11}\right)=\frac{\varepsilon_{11}^{F T(C)}}{\varepsilon_{11}^{F T(C)}-\varepsilon_{11}^{O T(C)}}\left(1-\frac{\varepsilon_{11}^{O T(C)}}{\varepsilon_{11}^{T(C)}}\right)
$$

where the same damage parameter was used to degrade the transmitted stress (c.f. Eqn. 11 in [23]). Mesh objectivity of the model was achieved by employing the crack-band model of Bažant and Oh [24], where a characteristic length of the finite element (equivalent to a RVE), $l_{f i b}$, and the corresponding fracture toughness, $\Gamma_{11}^{T(C)}$, were used. The failure strain, at which net-section fracture across the element occurs, was determined by the critical energy release rate, characteristic length and longitudinal strength, $X^{T(C)}$,

$$
\varepsilon_{11}^{F T(C)}=\frac{2 g_{11}^{T(C)}}{X^{T(C)}}=\frac{2 \Gamma_{11}^{T(C)}}{X^{T(C)} l_{f i b}}
$$

An accurate measure of the characteristic length is the ratio of the elemental volume $V$ and fracture plane area $A$,

$$
l_{\text {fib }}=\frac{V}{A}
$$

where $A$ is calculated using an approach proposed in [21] and described in Section 2.1.2.

\subsubsection{Matrix failure modes}

Matrix failure is characterised by matrix cracking, which could be the result of a combination of transverse (22), through-thickness (33) and shear stresses (12, 13 and 23). In contrast to the assumptions made for fibre-dominated failure modes, the transverse response is governed by the orientation of the fracture plane, which may not necessarily be normal to the loading direction. For tensile loading, this fracture plane will be normal to the load but as suggested by Puck and Schürmann [3], under compressive and/or shear loading, the failure plane orientation is determined by the ability of the matrix to withstand shear loading. The damage initiation and the subsequent progression of damage were calculated on the fracture plane as shown in Fig. 3. The stress tensor on the fracture plane was rotated using the standard transformation matrix $T(\theta)$. Page 7 of 53 


$$
\sigma_{L N T}=[T(\theta)] \sigma_{123}[T(\theta)]^{T}
$$

INSERT: Fig. 3. Material coordinate system (123) rotated to the fracture plane coordinate system (LNT)

\section{Non-linear shear response}

The matrix failure initiation criterion is based on the stress state acting on the fracture plane, assuming a pre-damage linear normal stress $\sigma_{N N}$ and non-linear shear stresses $\tau_{L N(N T)}$. In this context, the non-linear shear stress profiles were defined by a cubic law, obtained using a least square fitting method to experimental data,

$$
\tau\left(\gamma_{i j}\right)=c_{1} \gamma_{i j}^{3}-s g n\left(\gamma_{i j}\right) c_{2} \gamma_{i j}^{2}+c_{3} \gamma_{i j}
$$

where $c_{i}$ are the corresponding coefficients. Similar to the fibre-dominated damage, the transverse stress transmitted is linearly degraded by damage. The non-linear shear is expressed as the sum of an elastic and inelastic component,

$$
\gamma_{i j}=\gamma_{i j, e l}+\gamma_{i j, \text { in }} \quad i \neq j
$$

Prior to damage initiation, shear loading and unloading occurs along gradients defined by the initial shear modulus $G_{i j}$, shown by paths 1 and 2 in Fig. 4 . When damage is triggered, at $\tau_{0}$, the response follows a negative tangent stiffness resulting in the softening of the secant shear modulus, with increasing applied strain, to $\left(1-d_{m a t}\right) G_{i j}$, shown by path 3. Isotropic hardening was adopted to deal with load reversal.

INSERT: Fig. 4. Non-linear shear curve with different loading/unloading paths 


\section{Matrix damage initiation}

Puck's criterion is widely used for predicting matrix-dominated damage behaviour. However, this criterion does not account for in-situ effects, i.e., where the effective shear strength of a ply may be shown to increase when embedded in a multidirectional laminate. Moreover, for matrix tensile failure, this criterion provides reasonable predictions only if certain relations between material strengths are satisfied. For instance, under pure transverse tension, the criterion provides correct predictions only if $Y^{T} \leq \sqrt{2} S_{23}$, where $Y^{T}$ is the transverse tensile strength and $S_{23}$ is the transverse shear strength. The failure initiation criterion, taking into account the in-situ effect based on Catalanotti et.al.[25], overcomes this limitation and was adopted in the damage model.

If the normal stress in the fracture plane is compressive, $\sigma_{N N} \leq 0$, then

$$
F(\theta)=\left(\frac{\tau_{L N}}{S_{12}^{i s}-\mu_{L N} \sigma_{N N}}\right)^{2}+\left(\frac{\tau_{N T}}{S_{23}^{i s}-\mu_{N T} \sigma_{N N}}\right)^{2}
$$

and if the normal stress in the fracture plane, is tensile, $\sigma_{N N}>0$

$$
F(\theta)=\left(\frac{\sigma_{N N}}{S_{23}^{i s}}\right)^{2}+\left(\frac{\tau_{L N}}{S_{23}^{i s}}\right)^{2}+\left(\frac{\tau_{N T}}{S_{23}^{i s}}\right)^{2}+\lambda\left(\frac{\sigma_{N N}}{S_{23}^{i s}}\right)\left(\frac{\tau_{L N}}{S_{12}^{i s}}\right)^{2}+\kappa\left(\frac{\sigma_{N N}}{S_{23}^{i s}}\right)
$$

where parameters $\kappa$ and $\lambda$ are given by $\kappa=\frac{\left(S_{12}^{i s}\right)^{2}-\left(Y^{T, i s}\right)^{2}}{S_{23}^{i s} Y^{T, i s}}, \lambda=\frac{2 \mu_{L N} S_{23}^{i s}}{S_{12}^{i s}}-\kappa, Y^{T, i s}$ is the in-situ transverse shear strength and $S_{12}^{i s}$ and $S_{23}^{i s}$ are the in-situ shear strengths. The transverse friction

coefficients, defined in [6], are based on Mohr-Coulomb theory where $\mu_{N T}=-\frac{1}{\tan \left(2 \theta_{f}\right)}$,

$S_{23}^{i s}=\frac{Y^{C, i s}}{2 \tan \left(\theta_{f}\right)}$, where $Y^{C, i s}$ is the in-situ transverse compressive strength, and $\mu_{L N}=\frac{S_{12}^{i s}}{S_{23}^{i s}} \mu_{N T}$. The Page 9 of 53 
fracture plane orientation, $\theta_{f}$, is typically found to be approximately $53^{\circ}$ for unidirectional composites [6] under uniaxial transverse compressive loading. For a general 3D load state, the orientation is not known a priori and is determined by the angle which maximizes the failure criteria functions of Eqn (13) or Eqn (14). Brent's algorithm [26] was used for this purpose which combines a golden section search with parabolic interpolation.

\section{Matrix mixed-mode damage propagation}

Matrix failure is attributed to loading in transverse compression and shear. Once damage initiates, the stresses on the fracture plane and the characteristic length are recorded. A single damage parameter, $d_{\text {mat }}$, was used to define the degradation of the combined stress state, $\sigma_{r}$,

$$
\sigma_{r}=\sqrt{\sigma_{N N}^{2}+\left(\sigma_{N T}\right)^{2}+\left(\sigma_{N L}\right)^{2}}
$$

with corresponding strain, $\varepsilon_{r}$, acting on the fracture plane [7, 10], defined as the vector sum of the elastic and inelastic components, $\varepsilon_{r}=\varepsilon_{r, e l}+\varepsilon_{r, i n}$, where

$$
\begin{gathered}
\mathcal{E}_{r, e l}=\sqrt{{\mathcal{E}_{N N}}^{2}+\left(\gamma_{N T}^{e l}\right)^{2}+\left(\gamma_{N L}^{e l}\right)^{2}} \\
\varepsilon_{r, i n}=\sqrt{\left(\gamma_{N T}^{i n}\right)^{2}+\left(\gamma_{N L}^{i n}\right)^{2}}
\end{gathered}
$$

and $x=\max (0, x)$ is the McCauley operator. Fig. 5 shows the overall damage propagation for mixed-mode matrix damage where

$$
d_{\text {mat }}=\frac{\mathcal{E}_{r}^{f}-\varepsilon_{r, \text { in }}^{0}}{\mathcal{E}_{r}^{f}-\varepsilon_{r}^{0}}\left(\frac{\varepsilon_{r}^{0}-\varepsilon_{r}}{\mathcal{E}_{r}-\varepsilon_{r, \text { in }}^{0}}\right)
$$

The shear stresses on the fracture plane are degraded by the matrix damage parameter $d_{\text {mat }}$,

Page 10 of 53 


$$
\begin{gathered}
\sigma_{L N}=\left(1-d_{m a t}\right) \tilde{\sigma}_{L N}, \\
\sigma_{N T}=\left(1-d_{m a t}\right) \tilde{\sigma}_{N T}, \\
\sigma_{N N}=\tilde{\sigma}_{N N}-d_{m a t} \tilde{\sigma}_{N N} .
\end{gathered}
$$

These stresses are then transformed back to the material coordinate system to form the complete stress tensor of the damaged element.

The overall shear loading and unloading, prior to damage initiation, (Fig. 5) occurs along gradients defined by the initial shear modulus $G_{r}$, given by,

$$
G_{r}=\frac{\sigma_{r}^{0}}{\varepsilon_{r, e l}^{0}}
$$

INSERT: Fig. 5. Mixed-mode matrix damage evolution

The corresponding damage parameter, $d_{\text {mat }}$, is assumed to be a function of the resultant strain, $\varepsilon_{r}^{0}$, at damage initiation and the failure resultant strain, $\varepsilon_{r}^{f}$, which is governed by the mixed-mode critical strain energy release rate, $\Gamma_{r}$ and characteristic length, $l_{\text {mat }}$, given in the next section,

$$
\mathcal{E}_{r}^{f}=\frac{2}{\sigma_{r}^{0}}\left(\frac{\Gamma_{\mathrm{r}}^{\mathrm{C}}}{l_{\text {mat }}}-g_{0}\right)+\varepsilon_{r}^{0}
$$

The volumetric strain energies, at damage initiation, associated with each stress component on the fracture plane, are combined using a quadratic relationship, which can be represented by the dashed region in Fig.5,

$$
g_{0}=g_{N N}^{0}\left(\frac{\sigma_{N N}^{0}}{\sigma_{r}^{0}}\right)^{2}+g_{L N}^{0}\left(\frac{\tau_{L N}^{0}}{\sigma_{r}^{0}}\right)^{2}+g_{N T}^{0}\left(\frac{\tau_{N T}^{0}}{\sigma_{r}^{0}}\right)^{2}
$$


The volumetric strain energy associated with each stress component, $g_{i}^{0}$, where $i$ denotes $N N, L N$ and $N T$, is given by

$$
g_{i}^{0}=\int_{0}^{\varepsilon_{i}^{0}} \sigma_{i} d \varepsilon_{i}
$$

The critical mixed-mode strain energy release rate, $\Gamma_{r}^{C}$, is then given by

$$
\Gamma_{\mathrm{r}}^{\mathrm{C}}=\Gamma_{22}^{C}\left(\frac{\sigma_{N N}^{0}}{\sigma_{r}^{0}}\right)^{2}+\Gamma_{12}^{C}\left(\frac{\tau_{L N}^{0}}{\sigma_{r}^{0}}\right)^{2}+\Gamma_{23}^{C}\left(\frac{\tau_{N T}^{0}}{\sigma_{r}^{0}}\right)^{2}
$$

where $\Gamma_{i j}^{C}(i j=22,12,23)$, are the corresponding critical strain energy release rates for each stress component. The blue area, in Fig.5, is the inelastic strain energy density, $g_{\text {in }}$,

$$
g_{\text {in }}=g_{o}-\sigma_{r}^{0} \varepsilon_{r, e l}^{0} / 2
$$

\section{Characteristic length calculation}

The characteristic length given by ABAQUS is the cubic root of the volume of the element, which is only accurate when elements have aspect ratios close to unity and crack planes are assumed to evolve perpendicular to the midplane of the element. Therefore, a much more accurate measure of characteristic length should be calculated as a function of the crack plane orientation.

INSERT: Fig. 6. Calculation of the characteristic length

The fracture surface is defined by a unit normal vector $(\boldsymbol{n})$ in an arbitrary hexahedral element (Fig.6) [21]. This normal vector contains information on the material coordinate system as well as the fracture plane rotation.

Page 12 of 53 
The characteristic length algorithm determines the points, $\boldsymbol{p}_{\boldsymbol{i}}$, where the fracture plane intersects the element edges formed by connecting adjacent nodes. The triangular areas, $\boldsymbol{A}_{i}$, enclosed by adjacent intersection points, $\boldsymbol{p}_{\boldsymbol{i}}$, and the centre are then determined, Eqn (27). Their summation, Eqn (28) gives the total fracture plane area. This calculation is completed for each element in the model.

$$
\begin{gathered}
A_{i}=\frac{1}{2}\left(\vec{p}_{i} \times \vec{p}_{i+1}\right) \\
A=\sum A_{i}
\end{gathered}
$$

An upper limit is imposed on the characteristic length to mitigate inadmissible behaviour, hence restricting the maximum size of elements in the model, which is given by,

$$
\begin{gathered}
\boldsymbol{l}_{c}=\frac{V}{A} \leq \frac{2 \Gamma}{X \varepsilon} \\
l_{c}=\left\{\begin{array}{cc}
l_{f i b}, \quad(\Gamma, X, \varepsilon)=\left(\Gamma_{11}^{T(C)}, X^{T(C)}, \varepsilon_{11}^{0 T(C)}\right) \\
l_{\text {mat }}, \quad(\Gamma, X, \varepsilon)=\left(\Gamma_{22}^{T(C)}, Y^{T(C)}, \varepsilon_{22}^{0 T(C)}\right) \\
(\Gamma, X, \varepsilon)=\left(\Gamma_{i j}, S_{i j}, \gamma_{i j}^{0}\right) \quad i j=12,23,32
\end{array}\right.
\end{gathered}
$$

Using the material properties in Table $1, l_{c} \leq 1.664 \mathrm{~mm}$.

\subsection{Interlaminar damage model}

The in-built surface-based cohesive behaviour in ABAQUS/Explicit [27] was used to capture delamination using a bilinear traction-separation relationship. This approach is a convenient means to model the cohesive connections without the need to define cohesive elements and tie constraints. Failure initiation was governed by a quadratic stress criterion, 


$$
\left(\frac{\tau_{1}}{\tau_{1}^{0}}\right)^{2}+\left(\frac{\tau_{2}}{\tau_{2}^{0}}\right)^{2}+\left(\frac{\tau_{3}}{\tau_{3}^{0}}\right)^{2} \leq 1
$$

where $\tau_{i}(i=1,2,3)$ are the stresses in the in-plane directions and normal direction respectively, and $\tau_{i}^{0}$ are the corresponding maximum stresses associated with each direction. Delamination was propagated using a mixed-mode relationship proposed by Benzeggagh and Kenane (B-K propagation criterion) [28],

$$
G_{c}=G_{I c}+\left(G_{I I c}-G_{I c}\right) \mathrm{B}^{\eta}
$$

where $G_{c}$ is the mixed-mode fracture toughness, $\mathrm{B}$ is the local mixed-mode ratio defined as

$\mathrm{B}=G_{\text {shear }} /\left(G_{I}+G_{\text {shear }}\right)$. As mode III is not considered, $G_{\text {shear }}=G_{I I} . \eta$ is the mixed-mode interaction determined from experimental measurements provided in [29]. A penalty interface stiffness $k=\alpha E_{22} / t_{p}=7.4 \times 10^{5} \mathrm{~N} / \mathrm{mm}^{3}$ was chosen according to [30], where $\alpha$ is a coefficient set at 50, $E_{22}$ is the transverse Young's modulus of the composite and $t_{p}$ is the thickness of an adjacent double-ply $(0.52$ $\mathrm{mm})$.

To represent the distribution of tractions ahead of the crack tip accurately, at least three elements in the cohesive zone are required [30]. The cohesive zone length was estimated as [19]

$$
l_{c z}=\frac{9}{32} \pi E_{m} \frac{G_{c}}{\left(\tau^{0}\right)^{2}}
$$

where $E_{m}$ is the modulus of the interface material which approximately equals the transverse modulus, $E_{22}$, $G_{c}$ is the fracture toughness and $\tau^{0}$ is the nominal interfacial strength, defined by $\tau^{0}=\sqrt{\left(\tau_{s h}^{0}\right)^{2}+\left(\tau_{3}^{0}\right)^{2}}$

where $\tau_{s h}^{0}=\sqrt{\left(\tau_{1}^{0}\right)^{2}+\left(\tau_{2}^{0}\right)^{2}}$, for a specified mixed-mode ratio. The maximum size of cohesive elements is therefore defined by $l_{e}=l_{c z} / 3$. To avoid using very fine meshes which is computational expensive, Turon et al. [30] proposed the use of a lower interface strength with a coarser mesh size, which can still accurately capture the softening behaviour ahead of the crack tip. In this context, a nominal interface strength, Page 14 of 53 
$\tau^{0}=40 M P a$ yields a cohesive zone length of $l_{c z} \approx 5.1 \mathrm{~mm}$, and a maximum element size, $l_{e}=\frac{l_{c z}}{3}=1.71 \mathrm{~mm}$. The final element size $L e$ selected was $1.5 \mathrm{~mm}$ determined by taking into account both intralaminar and interlaminar characteristic lengths, i.e. $\operatorname{Le} \leq \min \left\{l_{c}, l_{e}\right\}$.

The interface was implemented using the penalty contact algorithm with a friction coefficient of 0.3 defined for all ply-to-ply contact. The visualization of the damage can be seen using the CSDMG surface variable (overall value of the scalar damage variable) available in the ABAQUS [27] output deck.

To verify the implementation of the surface-based cohesive behaviour, standard double cantilever beam $(D C B)$ and end-notch flexural (ENF) tests were performed using mesh sizes of $1.5 \mathrm{~mm}$ and $0.3 \mathrm{~mm}$ with different interface strengths $\tau^{0}$. The results were compared with analytical expressions obtained using LEFM. As shown in Fig.7 and Fig.8, the tests show that with lower interface strengths, the coarser mesh can still achieve a good level of accuracy.

INSERT: Fig. 7. (A)DCB simulation with mesh size of $1.5 \mathrm{~mm}$ (B) Load-displacement curve for different mesh densities

INSERT: Fig. 8. (A)ENF simulation with mesh size of $1.5 \mathrm{~mm}$ (B) Load-displacement curve for different mesh densities

\section{Finite element model}

Experimental results taken from [20] were used to validate the damage model. The virtual tests set up in ABAQUS 6.12/Explicit were executed in three steps, one to capture the impact damage, the second to stabilize the specimen by imposing new boundary conditions required for the compression testing and the third Page 15 of 53 
to predict the CAI strength. The composite damage model was implemented as a VUMAT subroutine. The code itself supports both single and double precision. However, as the simulations require a large number of increments, double precision was used to minimise round-off error.

INSERT: Fig. 9. (A) Impact and (B) CAI test setup

\subsection{Low velocity impact test}

T700/M21 and T700GC/M21 (see Table 1 for material properties) unidirectional carbon/epoxy laminates $\left[02,45_{2}, 90_{2},-45_{2}\right]_{s}$ were impacted using a drop tower system, with a $16 \mathrm{~mm}$ diameter, $2 \mathrm{~kg}$ impactor, following the Airbus Industries Test Method (AITM 1-0010 [31]). The rectangular laminates measured $100 \times 150 \times 4.16 \mathrm{~mm}^{3}$ (ply thickness, $t=0.26 \mathrm{~mm}$ ) and were placed on a frame of the same size, leaving an inner unsupported region of $75 \mathrm{~mm} \times 125 \mathrm{~mm}$ (Fig. 9A). Four panels were each impacted with different energies (6.5J, $17 \mathrm{~J}, 25 \mathrm{~J}$ and $29.5 \mathrm{~J})$. The $6.5 \mathrm{~J}, 17 \mathrm{~J}$ and $29.5 \mathrm{~J}$ impacted panels were manufactured from T700/M21 and the 25J impacted panel from T700GC/M21. The impactor was modelled as a spherically shaped rigid surface, with a reference lumped mass of $2 \mathrm{~kg}$. As the lay-up had paired plies, only one element through the thickness of each paired ply was used to reduce computational time.

\subsection{CAl test}

Once the impact simulation was completed, the damaged specimen was first stabilized by replacing the impact boundary conditions with those representing a picture frame clamped around the specimen to yield a $90 \mathrm{~mm} \times 130 \mathrm{~mm}$ test section. The out-of-plane displacements of the nodes, in contact with the picture frame, were constrained to represent a fixed boundary condition (Fig. 9B).

Although the CAI test is essentially quasi-static $(0.5 \mathrm{~mm} / \mathrm{min})$, it was simulated using ABAQUS/Explicit to avoid the severe convergence difficulties encountered with implicit analysis when modelling highly nonlinear behaviour. The load rate was chosen at $3.75 \mathrm{~m} / \mathrm{min}$ to reduce CPU time. Selective mass scaling, which Page 16 of 53 
only scaled elements whose stable time increment was below 1e-07s (controlled by the contact algorithm of cohesive surfaces due to the zero-thickness), was only employed in the CAI process to achieve a reasonable run time.

\subsection{Material properties}

Material properties for T700/M21 were obtained from [20] and those for T700GC/M21 from a related reference [12]. The coefficients, $\mathrm{c}_{i}(i=1,2,3)$, for the non-linear shear response were obtained using a least square fitting technique of experimental data presented in [32]. $\Gamma_{j j}^{d i r}$ denotes the longitudinal $(j j=11)$ and transverse $(j j=22)$ intralaminar fracture toughness in tension $(\operatorname{dir}=\mathrm{T})$ or compression $(\mathrm{dir}=\mathrm{C}) . G_{I}$ and $G_{I I}$ are the interlaminar fracture toughness for Mode I and Mode II. The mode mixity parameter, $\eta$, was determined from experimental measurements provided by Prombut et al.[29] using the method of least squares.

INSERT: Table 1. Material properties for T700/M21 [20,12]

\subsection{Element control}

In this simulation, the central region of the model was meshed with $1.5 \mathrm{~mm} \times 1.5 \mathrm{~mm} \times 0.26 \mathrm{~mm}$ C3D8R elements with one element through the thickness of each double ply of the laminate. To suppress spurious energy modes associated with the use of elements with reduced integration, an enhanced stiffnessbased hourglass and distortion control were employed. The degradation of element stiffness may result in high element distortion which may cause the simulation to abort prematurely, To mitigate this, an element was

deleted when the fibre-dominated longitudinal damage parameter, $d_{11}^{T(C)}>0.99$ and maximum shear strain $\operatorname{Max}\left(\gamma_{12(23,13)}\right)>1.0$ were both satisfied. The quoted values are user defined and were found to yield good results.

\section{Page 17 of 53}




\subsection{Contact algorithm}

The general contact algorithm available in ABAQUS/Explicit was used to simulate contact in the numerical model accounting for contact forces that resist node-face, node-analytical surface, and edge-edge contact penetrations for any ply-ply or impactor-ply contact which may arise in the model, including ply-ply contact of initially non-contiguous plies. For contact between the impactor and composite laminate, and ply-toply contact, a friction coefficient of 0.3 [7] was used.

\subsection{Computational cost}

The final FE models each contained a total of 46072 C3D8R elements. Models were run on a Windows Cluster with 32 cores. Each complete simulation (Impact and CAI) took between 19 and 21 hours, depending on impact energy levels.

\section{Results and discussion}

\subsection{Low velocity impact test}

\subsubsection{Global impact response}

With reference to Figure 10, the extent of experimental data available varied between the tests reported for different impact energies. For example, the complete history of the contact force of the impactor versus time was only reported for the $25 \mathrm{~J}$ impact on the panel manufactured from T700GC/M21 (Fig 10C). This shows very good agreement, with the predicted maximum force being $6.8 \%$ higher than the one measured experimentally. The predicted peak forces for the 6.5J (Fig 10A) and 29.5J (Fig 10D) impacts also correlated well with experimental results, where the numerical peak loads were $3.2 \%$ and $6.7 \%$ higher than experimental tests, respectively. No peak load information was reported for the $17 \mathrm{~J}$ impact test but the numerical impact-force versus time results are included for completeness.

\section{Page 18 of 53}


INSERT: Fig. 10. Impact force-time curves (A) $6.5 \mathrm{~J} \mathrm{(B)} 17 \mathrm{~J}$ (C) 25J (D) 29.5J

The impact force-displacement histories in Fig. 11 (denoted by 'Num') correlate well with the experimental results (denoted by 'Exp') recorded for the 6.5J (Fig. 11A), 25J (Fig. 11C) and 29.5J (Fig. 11D) impact tests. The initial contact response, maximum displacements of the impactor and the rebound process were all captured with good accuracy. It was observed that increasing the impact energy lead to a corresponding increase in the maximum displacement and energy absorbed. The enclosed area within the loading and unloading curves is a measure of the energy dissipated (or absorbed) due to damage in the laminates. The dissipation energies, computed from the finite element analyses, were consistent with those calculated from the change in kinetic energy of the impactor. Fig. 11E shows this change in energy for the four test cases, where $E_{a}$ represents the energy absorbed during the $29.5 \mathrm{~J}$ impact event. No force-displacement data was available for the $17 \mathrm{~J}$ impact case. Numerical results predicted that the $6.5 \mathrm{~J}$ impact case would absorb $2.35 \mathrm{~J}$, followed by $6.94 \mathrm{~J}, 12.18 \mathrm{~J}$ and $14.24 \mathrm{~J}$ for impact energies $17 \mathrm{~J}, 25 \mathrm{~J}$ and $29.5 \mathrm{~J}$ respectively.

INSERT: Fig. 11. Impact force-displacement curves (A) 6.5J (B) 17J (C) 25J (D) 29.5J and (E) Energytime curve

\subsubsection{Matrix damage and delamination}

Matrix cracking was found to be the dominant form of intralaminar failure for the range of impact energies investigated, with little evidence of fibre breakage. Fig. 12 shows a superposition of intralaminar matrix damage predicted by the damage model. Matrix cracking was concentrated around the impact region with a symmetric and continuous distribution similar to that reported in [10]. The extent of matrix cracking is shown to increase in proportion to the increase in impact energy.

INSERT: Fig. 12. Intralaminar matrix impact damage envelopes (A) 6.5J (B) 17J (C) 25J (D) 29.5J Page 19 of 53 
Delamination contours at each ply-pair interface were superimposed and compared to an outline of C-Scan data obtained from reference [20] and presented in Fig. 13. Delaminations at the bottom $45^{\circ} / 0^{\circ}$ interface, for the $25 \mathrm{~J}$ and $29.5 \mathrm{~J}$ impact cases, tended to propagate along the $0^{\circ}$ direction in the C-scan images presented in [20] whereas the present analysis shows propagation predominantly along the $45^{\circ}$ direction. The C-scan contours for these two impact cases have been rotated to reflect this propagation preference. The predicted delamination areas, listed in Fig. 13, show good agreement with the experimental/C-scan areas.

INSERT: Fig. 13. Delamination damage envelope compared with experimental C-scan outlines (A) $6.5 \mathrm{~J}$ (B) $17 \mathrm{~J}(\mathrm{C}) 25 \mathrm{~J}(\mathrm{D}) 29.5 \mathrm{~J}$

Fig.14A shows matrix cracking and delamination for each double-ply and interface, respectively, for the $29.5 \mathrm{~J}$ impact case. Delaminations at each interface were deduced from the damage variable associated with surface-based cohesive behaviour (through variable CSDMG). The shape and size of delaminations are similar to the matrix damage areas except for the $90^{\circ}$ plies which seem to show extensive damage extending to the boundary. A similar observation was made in the damage model proposed by Raimondo et al.[10] but no explanation was given. One possible explanation concerns the sensitivity to the relative strength and toughness values used for interlaminar (delamination) and intralaminar matrix damage. For a given impact energy, it has already been shown that excellent correlation was achieved in predicting the impactor force-time and displacement-time histories, indicating that the overall energy dissipation is well predicted. Increasing the damage initiation strength for intralaminar matrix damage, as shown in Fig 14B to explore in-situ effects and discussed in more detail below, has a significant influence on the ratio of delamination to intralaminar matrix damage. Fine-tuning these values through accurate material characterisation testing should yield a better partition of these different matrix damage modes, whilst maintaining an accurate estimate of the overall energy dissipation due to matrix damage. The maximum delaminated area occurred at the $45^{\circ} / 0^{\circ}$ interface close to Page 20 of 53 
the bottom surface. The predicted intralaminar matrix damage envelopes followed the expected behaviour, developing in the direction parallel to the fibre orientation.

The transverse tensile strength $Y^{T}=60 M P a$ and shear strength $S_{12}=110 M P a$ used in this paper were not modified to account for in-situ effects although such effects were investigated and found to yield comparatively poor results as discussed below. Dvorak and Laws [33] calculated the transition thickness between a thin and a thick ply to be approximately $0.7 \mathrm{~mm}$ for carbon/epoxy laminates. Since double plies were modelled as one layer $(0.52 \mathrm{~mm})$ in the simulation, the in-situ strength values were evaluated using the thin ply equation presented by Camanho et al.[34] as an approximation,

$$
\begin{gathered}
Y^{T, i s}=\sqrt{\frac{4 G_{I c}}{\pi t_{p}\left(\frac{1}{E_{22}}-\frac{v_{21}^{2}}{E_{11}}\right)}}=97.4 \mathrm{MPa} \\
S_{12}^{i s}=\left\{\begin{array}{l}
\sqrt{\frac{8 G_{12} G_{I I c}}{\pi t_{p}}}=193.98 \mathrm{MPa}, \text { thin embedded ply } \\
2 \sqrt{\frac{G_{12} G_{I I c}}{\pi t_{p}}}=137.16 \mathrm{MPa}, \text { thin outer ply }
\end{array}\right.
\end{gathered}
$$

Where $G_{I c}$ and $G_{I I c}$ are the mode I and mode II fracture toughness, $G_{12}$ is the shear modulus and $t_{p}$ is the double-ply thickness. The overall effect of including in-situ effects is to raise the apparent respective strengths. For simplicity, an average value of $S_{12}^{i s}=165.57 \mathrm{MPa}$ was used to represent the in-situ effect on shear strength, and different intralaminar matrix damage and delamination contours were obtained (Fig.14B) compared to those presented in Fig. 14A. Delamination become the major damage failure mode and intralaminar matrix damage areas were comparatively smaller, especially noticeable in the $90^{\circ}$ plies, presumably since higher strengths made it more difficult to initiate intralaminar matrix damage. The smaller area enclosed by the impact force-displacement curve, for the in-situ case, shown in Fig.11D, (denoted by Page 21 of 53 
'Num_in-situ') and the energy-time curve in Fig.16B, indicate less damage during the impact process. The strength values obtained from standard tests, i,e, without in-situ modifications, yielded better predictions in terms of the overall impact response, as can be seen in Fig.10D and Fig.11D. The influence of in-situ effects requires a more detailed study which is beyond the scope of the work presented.

INSERT: Fig.14. Damage contours for plate impacted with 29.5J (A) Strength values of a ply (B) In-situ strength values

\subsubsection{Permanent indentation}

The damage model has the capability of simulating the permanent indentation of composite laminates after the impactor has rebounded and transient vibrations have subsided. Fig 15A shows an image of the permanent indentation observed in the test while Fig 15B shows the out of-plane displacement contours from the analysis. The permanent indentation captured by the model shows that the central indentation depth is approximately $0.7 \mathrm{~mm}$, which is in good agreement with experimental measurements [20]. The capability of the FE model to capture permanent indentation is attributed to the nonlinear shear formulation of the intralaminar damage model. This deformation may be significant in defining the compression-after-impact response of the laminates [35]. As discussed in the formulation of the damage model, shear strain was decomposed into elastic strain $\gamma_{i j, e l}$ and inelastic strain $\gamma_{i j, \text { in }}$ components, the latter enabling the capture of post-impact indentation. The energy dissipated by plasticity is given by Fig. 15C, in which the inelastic energy is about one-third of the overall energy dissipated by the damage.

INSERT: Fig. 15. Permanent indentation after impact (A) Experimental results $(-0.7 \mathrm{~mm})[20]$; (B) Numerical results; (C) Energy dissipated by plasticity

\section{Page 22 of 53}




\subsubsection{Energy dissipation mechanisms}

As the impact event progresses, the energy absorbed by the laminates is mainly dissipated in the form of intralaminar matrix damage, fibre-dominated damage, delamination, and impactor-laminate and ply-ply friction. The absorbed energy of the laminate under an impact energy of 29.5J, and energy dissipated by each damage mechanism is shown in Fig. $16 \mathrm{~A}$ as a function of time. Most of the energy is dissipated by intralaminar matrix damage, which is consistent with the matrix-dominated damage envelope shown in Fig. 12D. The jump in fibre-dominated energy dissipation indicates that this failure mode occurs suddenly during the impact process. The total energy dissipated by these mechanisms almost equals the final energy absorbed of $14.24 \mathrm{~J}$, calculated from the change in kinetic energy of the impactor and confirming the energy balance relationship. The small discrepancy is due to the additional energy dissipated to control spurious zero energy modes which may occur in reduced integration elements. A different trend is shown in Fig.16B, where the use of 'in-situ' transverse tensile and shear strengths reduced the energy absorbed to $8.7 \mathrm{~J}$ and energy was mainly dissipated by delamination.

INSERT: Fig. 16. Overall damage dissipation mechanism for $29.5 \mathrm{~J}$ impact $29.5 \mathrm{~J}$ (A) Standard strength values of a ply (B) In-situ strength values

\subsection{CAl Test}

\subsubsection{Stress-displacement curve}

Applied stress versus end-displacement curves, obtained during CAI tests, show that excellent correlation was achieved with experimental results, Fig. 17. The response of a pristine panel has been included for comparison. For the $6.5 \mathrm{~J}$ impact case, the effect on stiffness is minimal. This is to be expected as impact-induced damage is not extensive. For the other cases, the reduction in stiffness is commensurate with the level of impact damage. Compared to experimental results, the ultimate stresses were predicted to within Page 23 of 53 
$10 \%$ of experiment results ( $7.7 \%$ for $6.5 \mathrm{~J}, 9.2 \%$ for $17 \mathrm{~J}$, and $9.3 \%$ for $29.5 \mathrm{~J}$ respectively). CAI data for the $25 \mathrm{~J}$ panel was not reported. Numerical results show that the damaged panels under $6.5 \mathrm{~J}, 17 \mathrm{~J}, 25 \mathrm{~J}$ and $29.5 \mathrm{~J}$ impact energy failed at $10.1 \%, 28.4 \%, 45.9 \%$ and $54.2 \%$, respectively, of the load carried by the pristine panel. Fig. 17E represents the CAI strength versus impact energy for the tested laminates, which confirms the high level of correlation achieved between experiment and numerical analysis.

INSERT: Fig. 17. CAI stress-displacement curves (A) 6.5J (B) 17J (C) 25J (D) 29.5J (E) CAl strength versus impact energy

\subsubsection{Intralaminar matrix damage}

A sequence of superimposed intralaminar matrix damage maps at different displacement, obtained from the virtual CAI test on the panel impacted with 29.5J, is shown in Fig. 18. The damage progression from Fig18(A) to Fig18(D) indicated that matrix damage also initiated from the two outer edges, due to free-edge effects, aligned with the central impacted region and propagated towards the damaged centre of the panel. Local sub-laminate buckling, at the failure site, is observed in Fig. 18E, which indicates the presence of extensive delamination (Fig. 21).

INSERT: Fig. 18. CAI matrix damage of 29.5J impact case at displacement of (A)0.6mm (B) $0.65 \mathrm{~mm}$ (C) $0.70 \mathrm{~mm}$ (D)0.75mm (E) Side View

The superimposed intralaminar matrix damage contours for all panels, at ultimate failure, are shown in Fig. 19. These confirm that damage propagated through the pre-damaged impacted centre of the panel which is consistent with experimental observations [36].

\section{Page 24 of 53}


INSERT: Fig. 19. CAI Matrix-dominated Damage (A) 6.5J (B) 17J (C) 25J (D) 29.5J

\subsubsection{Fibre-dominated damage}

The final compressive fibre-dominated damage maps, from the virtual CAI tests, are shown in Fig. 20. Complete fibre failure is observed through the width of the panel in the vicinity of the impact damage, with most damage observed in the outer $0^{\circ}$ plies and, to a lesser extent, in the $\pm 45^{\circ}$ plies. When the impact damage is low (Fig. 20A), fibre breakage is observed through the impacted site, characterised by a single dominant crack. As the energy increases, it is observed that multiple crack sites are predicted. This is supported by some CAI tests [37] where these impacted sites, which are more heavily damaged, will consequently shed more load into the neighbouring regions. This results in fibre breakage away from the impact site where the high curvatures associated with sub-laminate buckling leads to further fibre damage.

INSERT: Fig. 20. Fibre failure (A) $6.5 \mathrm{~J}$ (B) $17 \mathrm{~J}$ (C) $25 \mathrm{~J}$ (D) $29.5 \mathrm{~J}$

\subsubsection{Overall damage and energy dissipation mechanisms}

CAI damage plots for each ply pair and delaminations are shown in Fig. 21 for the $29.5 \mathrm{~J}$ impact case. During the CAI process, new delamination and intralaminar matrix damage developed from the impact-induced damage area. Fibre damage was primarily observed in the top and bottom plies. The predicted damage correlated well with experimental findings.

INSERT: Fig. 21. CAI damage contours for 29.5J impact case

Page 25 of 53 
The CAl energy dissipation curves in Fig.22 show that the rapid increase in fibre-dominated damage led to a corresponding sudden load drop under displacement control. This failure mode was also associated with the highest level of energy dissipation in comparison to the other damage mechanisms. This event was accompanied by rapid increases in delamination and intralaminar matrix damage and moderate increases in ply-to-ply friction.

INSERT: Fig. 22. CAI Energy dissipation curves for 29.5J impact case

\section{Conclusions}

A composite damage model that accounts for both intralaminar (matrix and fibre-dominated damage) and interlaminar (delamination) damage was presented which has shown a high degree of capability in predicting impact damage and compression-after-impact strength. This 3D model included an updated damage initiation criterion, an accurate characteristic length determination, a robust unloading/reloading mechanism and a unified matrix-dominated damage law.

The force-displacement curves, damage parameter maps and energy dissipated by each damage mechanism, obtained from the numerical analysis, demonstrate that the model can capture both the qualitative and quantitative aspects of intralaminar and interlaminar damage for a range of impact energies. Permanent indentation was captured which may have a significant influence on the CAI response. The CAI simulations predicted the complex damage features, and ensuing residual strength with a high degree of accuracy. This was achieved without the need to calibrate the input parameters which were obtained from reliable literature sources, following standard testing protocols. Future work will focus on extending this computational damage model to capture high energy crush events which will enable accurate assessments of crashworthiness of composite structures.

Page 26 of 53 


\section{Acknowledgement}

The corresponding author would like to acknowledge the financial support of Bombardier and the Royal Academy of Engineering. The authors would also like to gratefully acknowledge the funding from the Queen's University Belfast/China Scholarship Council (QUB/CSC) PhD Scholarship and the support from the Research Computing Team at QUB in accessing the HPC facilities.

\section{References}

[1] Kachanov LM. Introduction to Continuum Damage Mechanics. Boston: Martinus Nijhoff Publishers. 1986.

[2] Lemaitre J, Chaboche JL. Mechanics of solid materials. Cambridge, UK: Cambridge University Press; 1990.

[3] Puck A, Schürmann H. Failure analysis of FRP laminates by means of physically based phenomenological models. Compos Sci Technol. 1998;58(7):1045-67.

[4] Pinho S, Iannucci L, Robinson P. Physically based failure models and criteria for laminated fibre-reinforced composites with emphasis on fibre kinking. Part II: FE implementation. Composites Part A: Applied Science and Manufacturing. 2006;37(5):76677.

[5] Pinho S, Iannucci L, Robinson P. Physically-based failure models and criteria for laminated fibre-reinforced composites with emphasis on fibre kinking: Part I:

Development. Composites Part A: Applied Science and Manufacturing. 2006;37(1):63-73.

[6] Donadon MV, Iannucci L, Falzon BG, Hodgkinson JM, de Almeida SFM. A progressive failure model for composite laminates subjected to low velocity impact damage. Computers \& Structures. 2008;86(11-12):1232-52.

[7] Faggiani A, Falzon BG. Predicting low-velocity impact damage on a stiffened composite panel. Composites Part A: Applied Science and Manufacturing. 2010;41(6):73749.

[8] Falzon BG, Apruzzese P. Numerical analysis of intralaminar failure mechanisms in composite structures. Part I: FE implementation. Compos Struct. 2011;93(2):1039-46.

[9] Falzon BG, Apruzzese P. Numerical analysis of intralaminar failure mechanisms in composite structures. Part II: Applications. Compos Struct. 2011;93(2):1047-53.

[10] Raimondo L, Iannucci L, Robinson P, Curtis P. A progressive failure model for meshsize-independent FE analysis of composite laminates subject to low-velocity impact damage. Compos Sci Technol. 2012;72(5):624-32.

[11] Bouvet C, Rivallant S, Barrau JJ. Low velocity impact modeling in composite laminates capturing permanent indentation. Composites Science and Technology. 2012;72(16):1977-88.

Page 27 of 53 
[12] Hongkarnjanakul N, Bouvet C, Rivallant S. Validation of low velocity impact modelling on different stacking sequences of CFRP laminates and influence of fibre failure. Composite Structures. 2013;106(0):549-59.

[13] Uda N, Ono K, Kunoo K. Compression fatigue failure of CFRP laminates with impact damage. Composites Science and Technology. 2009;69(14):2308-14.

[14] Ghelli D, Minak G. Low velocity impact and compression after impact tests on thin carbon/epoxy laminates. Composites Part B: Engineering. 2011;42(7):2067-79.

[15] Petit S, Bouvet C, Bergerot A, Barrau J-J. Impact and compression after impact experimental study of a composite laminate with a cork thermal shield. Composites Science and Technology. 2007;67(15):3286-99.

[16] Williams G, Bond I, Trask R. Compression after impact assessment of self-healing CFRP. Composites Part A: Applied Science and Manufacturing. 2009;40(9):1399-406. [17] Vieille B, Casado VM, Bouvet C. Influence of matrix toughness and ductility on the compression-after-impact behavior of woven-ply thermoplastic- and thermosettingcomposites: A comparative study. Composite Structures. 2014;110(0):207-18.

[18] Davies GAO, Hitchings D, Besant T, Clarke A, Morgan C. Compression after impact strength of composite sandwich panels. Composite Structures. 2004;63(1):1-9.

[19] González E, Maimí P, Camanho P, Turon A, Mayugo J. Simulation of drop-weight impact and compression after impact tests on composite laminates. Composite Structures. 2012;94(11):3364-78.

[20] Rivallant S, Bouvet C, Hongkarnjanakul N. Failure analysis of CFRP laminates subjected to compression after impact: FE simulation using discrete interface elements. Composites Part A: Applied Science and Manufacturing. 2013;55:83-93.

[21] Chiu LN, Falzon BG, Boman R. A Continuum Damage Mechanics Model for the Analysis of the Crashworthiness of Composite Structures: A work in progress. Proceedings of the 15th Australian Aeronautical Conference. Melbourne2013.

[22] Van Paepegem W, De Baere I, Lamkanfi E, Degrieck J. Monitoring quasi-static and cyclic fatigue damage in fibre-reinforced plastics by Poisson's ratio evolution. International Journal of Fatigue. 2010;32(1):184-96.

[23] Turon A, Camanho PP, Costa J, Davila CG. A damage model for the simulation of delamination in advanced composites under variable-mode loading. Mech Mater.

2006;38(11):1072-89.

[24] Bažant ZP, Oh BH. Crack band theory for fracture of concrete. Matériaux et construction. 1983;16(3):155-77.

[25] Catalanotti G, Camanho P, Marques A. Three-dimensional failure criteria for fiberreinforced laminates. Compos Struct. 2012.

[26] Press WH. Numerical recipes in Fortran 77: the art of scientific computing: Cambridge university press; 1992.

[27] Systems D. ABAQUS Documentation 6.12. SIMULIA; 2012.

[28] Benzeggagh ML, Kenane M. Measurement of mixed-mode delamination fracture toughness of unidirectional glass/epoxy composites with mixed-mode bending apparatus. Composites science and technology. 1996;56:439-49.

[29] Prombut P, Michel L, Lachaud F, Barrau JJ. Delamination of multidirectional composite laminates at $0^{\circ} / \theta^{\circ}$ ply interfaces. Engineering Fracture Mechanics.

2006;73(16):2427-42.

Page 28 of 53 
[30] Turon A, Dávila CG, Camanho PP, Costa J. An engineering solution for mesh size effects in the simulation of delamination using cohesive zone models. Engineering Fracture Mechanics. 2007;74(10):1665-82.

[31] Method AIT. Determination of Compression Strength after Impact. AITM 1-0010; 2010.

[32] Preetamkumar M, Gilles L, Pierre L, Ana-cristina G. Validation of Intralaminar Behaviour of the Laminated Composites by Damage Mesomodel. 50th AIAA/ASME/ASCE/AHS/ASC Structures, Structural Dynamics, and Materials Conference: American Institute of Aeronautics and Astronautics; 2009.

[33] Dvorak GJ, Laws N. Analysis of progressive matrix cracking in composite laminates II. First ply failure. Journal of Composite Materials. 1987;21(4):309-29.

[34] Camanho PP, Dávila CG, Pinho ST, Iannucci L, Robinson P. Prediction of in situ strengths and matrix cracking in composites under transverse tension and in-plane shear. Composites Part A: Applied Science and Manufacturing. 2006;37(2):165-76.

[35] Sztefek P, Olsson R. Nonlinear compressive stiffness in impacted composite laminates determined by an inverse method. Composites Part A: Applied Science and Manufacturing. 2009;40(3):260-72.

[36] Yan H, Oskay C, Krishnan A, Xu LR. Compression-after-impact response of woven fiber-reinforced composites. Composites Science and Technology. 2010;70(14):2128-36. [37] Rivallant S, Bouvet C, Abi Abdallah E, Broll B, Barrau J-J. Experimental analysis of CFRP laminates subjected to compression after impact: The role of impact-induced cracks in failure. Composite Structures. 2014;111(0):147-57.

\section{Figure captions}

Fig. 1. Damage modes in laminated composites

Fig. 2. Bilinear law (shaded area is volumetric strain energy density)

Fig. 3. Material coordinate system (123) rotated to the fracture plane coordinate system (LNT)

Fig. 4. Non-linear shear curve with different loading/unloading paths

Fig. 5. Mixed-mode intralaminar matrix damage evolution

Fig. 6. Calculation of the characteristic length

Fig. 7. (A)DCB simulation with mesh size of $1.5 \mathrm{~mm}$ (B) Load-displacement curve for different mesh densities

Fig. 8. (A)ENF simulation with mesh size of $1.5 \mathrm{~mm}$ (B) Load-displacement curve for different mesh densities

Fig. 9. (A) Impact and (B) CAl test setup

Page 29 of 53 
Fig. 10. Impact force-time curves (A) $6.5 \mathrm{~J}$ (B) $17 \mathrm{~J}$ (C) 25J (D) 29.5J

Fig. 11. Impact force-displacement curves (A) 6.5J (B) 17J (C) 25J (D) 29.5J (E) energy-time curve

Fig. 12. Intralaminar matrix impact damage envelope (A) $6.5 \mathrm{~J}$ (B) $17 \mathrm{~J}$ (C) $25 \mathrm{~J}$ (D) 29.5J

Fig. 13. Delamination damage envelope compared with experimental C-scan outline (dash line) (A) 6.5J (B) $17 \mathrm{~J}(\mathrm{C}) 25 \mathrm{~J}$ (D) 29.5J

Fig. 14. Damage contours for plate impacted with $29.5 \mathrm{~J}$ (A) Standard strength values of a ply (B) In-situ strength values

Fig. 15. Permanent indentation after impact (A) Experimental results $(-0.7 \mathrm{~mm})[20]$; (B) Numerical results; (C) Energy dissipated by plasticity

Fig. 16. Overall damage dissipation mechanism for 29.5J impact (A) Standard strength values of a ply (B) Insitu strength values

Fig. 17. CAl stress-displacement curves (A) $6.5 \mathrm{~J}$ (B) $17 \mathrm{~J}$ (C) $25 \mathrm{~J}$ (D) 29.5J (E) CAl Strength versus impact energy

Fig. 18. CAl matrix damage of 29.5J impact case at displacement of (A) $0.6 \mathrm{~mm}(B) 0.65 \mathrm{~mm}(C) 0.70 \mathrm{~mm}$ (D) $0.75 \mathrm{~mm}$ (E) Side View

Fig. 19. CAI matrix-dominated damage (A) $6.5 \mathrm{~J}$ (B) $17 \mathrm{~J}$ (C) $25 \mathrm{~J}$ (D) 29.5J

Fig. 20. Fibre failure (A) $6.5 \mathrm{~J}$ (B) $17 \mathrm{~J}$ (C) $25 \mathrm{~J}$ (D) 29.5J

Fig. 21. CAl damage contours for $29.5 \mathrm{~J}$ impact case

Fig. 22. CAl energy dissipation curves for $29.5 \mathrm{~J}$ impact case

Table 1. Material Properties of T700/M21 for numerical simulation $[20,12]$

\begin{tabular}{ll}
\hline \multicolumn{1}{c}{ Property } & Values \\
\hline Elastic Properties & $\mathrm{E}_{1}=130 G P a ; \mathrm{E}_{2}=\mathrm{E}_{3}=7.7 G P a ; \mathrm{G}_{23}=3.8 G P a ;$ \\
& $\mathrm{G}_{12}=\mathrm{G}_{13}=4.8 G P a ; v_{12}=v_{13}=0.3\left(0.33^{a}\right) ; v_{23}=0.35$ \\
\hline \multirow{2}{*}{ Strength } & $\mathrm{X}^{\mathrm{T}}=2080 M P a ; \mathrm{X}^{\mathrm{C}}=1250 M P a ; \mathrm{Y}^{\mathrm{T}}=60 M P a ;$ \\
& $\mathrm{Y}^{\mathrm{C}}=120 \mathrm{MPa} ; \mathrm{S}_{12}=110 \mathrm{MPa}$ \\
\hline Intralaminar Fracture Toughness & $\Gamma_{11}^{\mathrm{T}}=133 \mathrm{~N} / \mathrm{mm} ; \Gamma_{11}^{\mathrm{C}}=10\left(40^{a}\right) \mathrm{N} / \mathrm{mm} ;$ \\
\hline
\end{tabular}

Page 30 of 53 


\begin{tabular}{ll}
\hline & $\Gamma_{22}^{\mathrm{T}}=0.5\left(0.6^{a}\right) \mathrm{N} / \mathrm{mm} ; \Gamma_{22}^{\mathrm{C}}=1.6\left(2.1^{a}\right) \mathrm{N} / \mathrm{mm} ;$ \\
& $\Gamma_{12}=\Gamma_{23}=\Gamma_{13}=1.6\left(2.1^{a}\right) \mathrm{N} / \mathrm{mm} ;$ \\
\hline Non-linear Shear Properties & $\mathrm{c}_{1}=37833 \mathrm{MPa} ; \mathrm{c}_{2}=16512 \mathrm{MPa} ; \mathrm{c}_{3}=2334.3 \mathrm{MPa}$ \\
& $G_{I C}=0.5\left(0.6^{a}\right) \mathrm{N} / \mathrm{mm} ; \mathrm{G}_{I I C}=1.6\left(2.1^{a}\right) \mathrm{N} / \mathrm{mm} ;$ \\
& $\eta=1.45 ; \tau_{3}^{0}=20 \mathrm{MPa} ; \tau_{s h}^{0}=36 \mathrm{MPa}$ \\
\hline
\end{tabular}

a Material : T700GC/M21 [12]

Page 31 of 53 


\section{FIGURES}

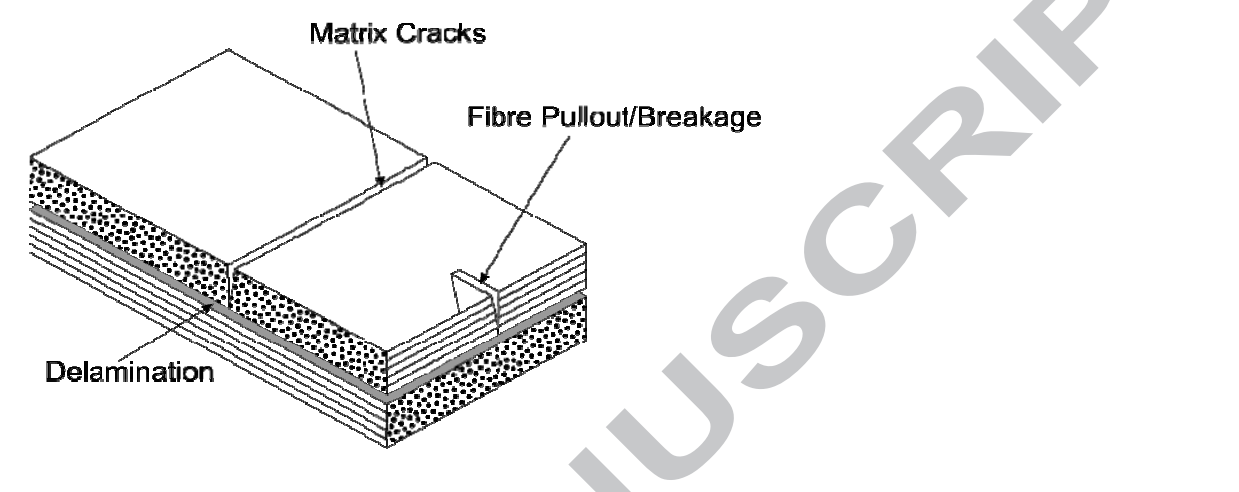

Fig. 1. Damage modes in laminated composites

Page 32 of 53 


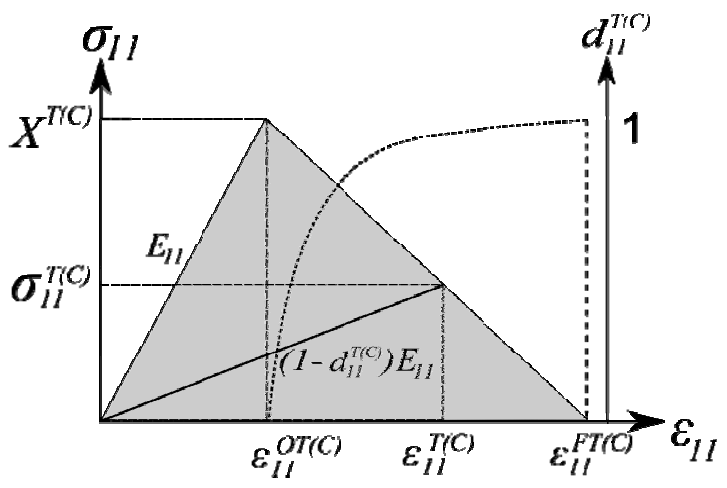

Fig. 2. Bilinear law (shaded area is volumetric strain energy density,

Page 33 of 53 


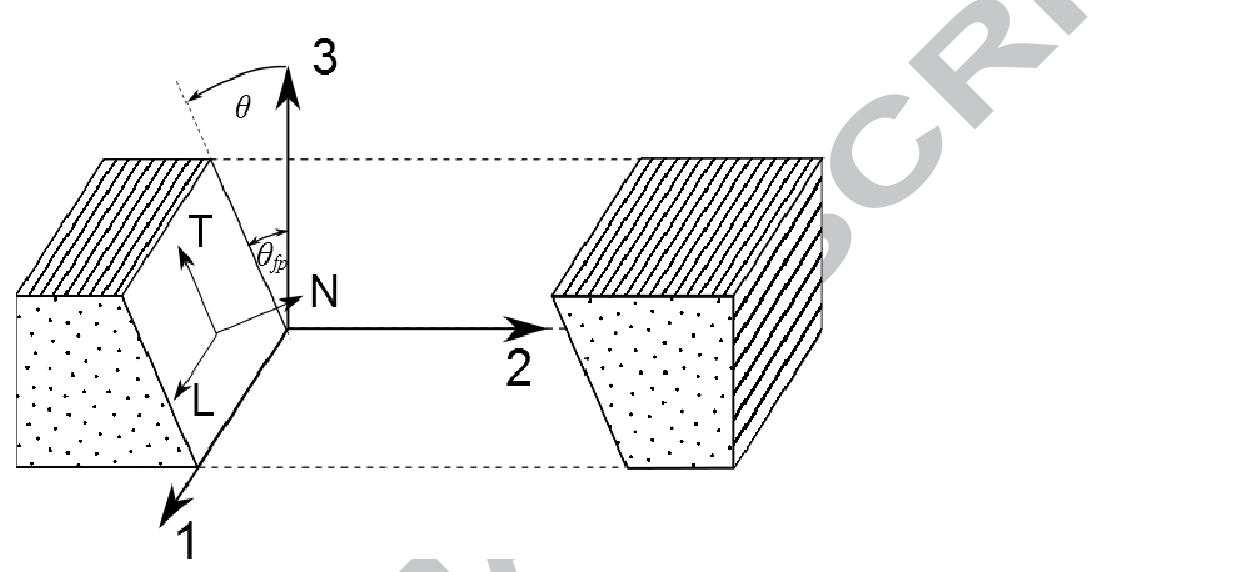

Fig. 3. Material coordinate system (123) rotated to the fracture plane coordinate system (LNT)

Page 34 of 53 


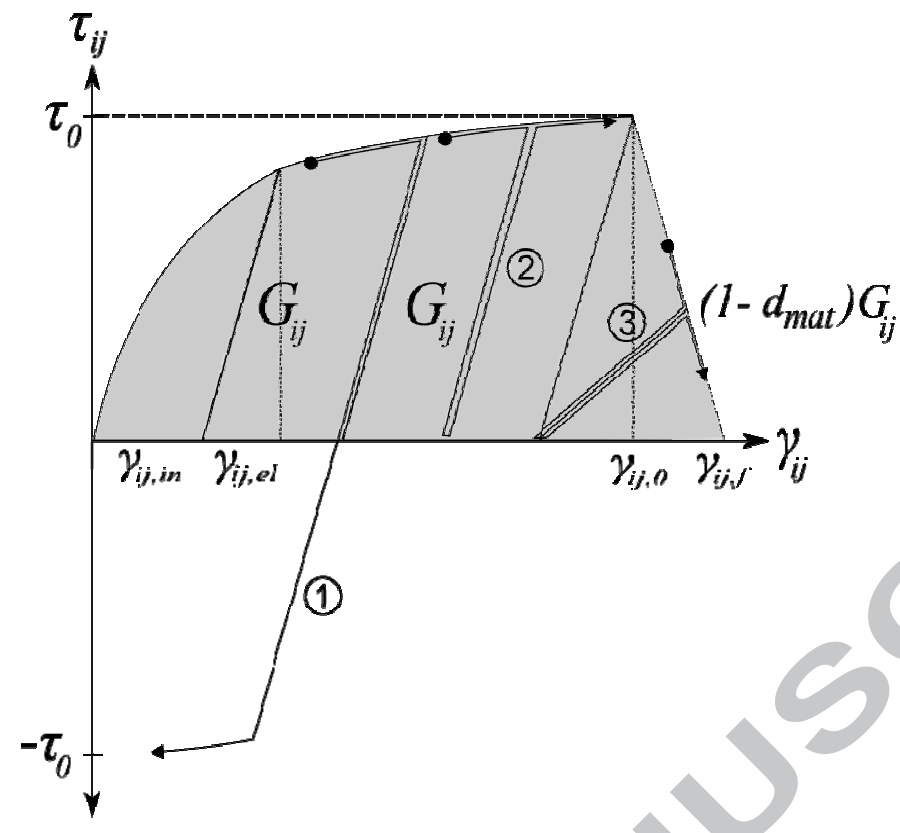

Fig. 4. Non-linear shear curve with different loading/unloading paths 


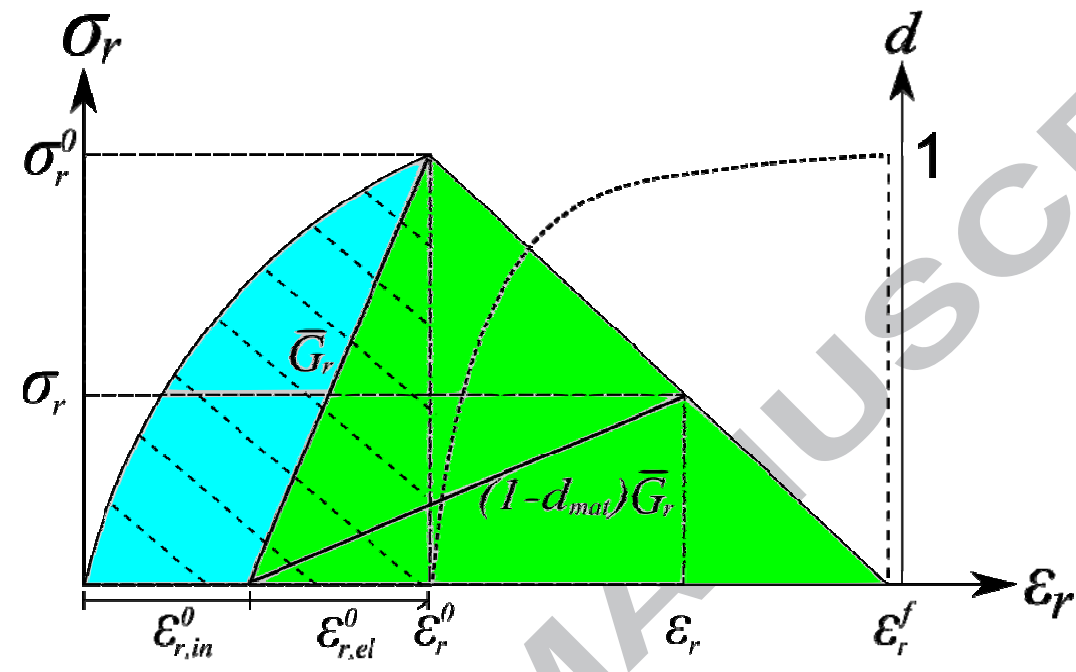

Fig. 5. Mixed-mode intralaminar matrix damage evolution 


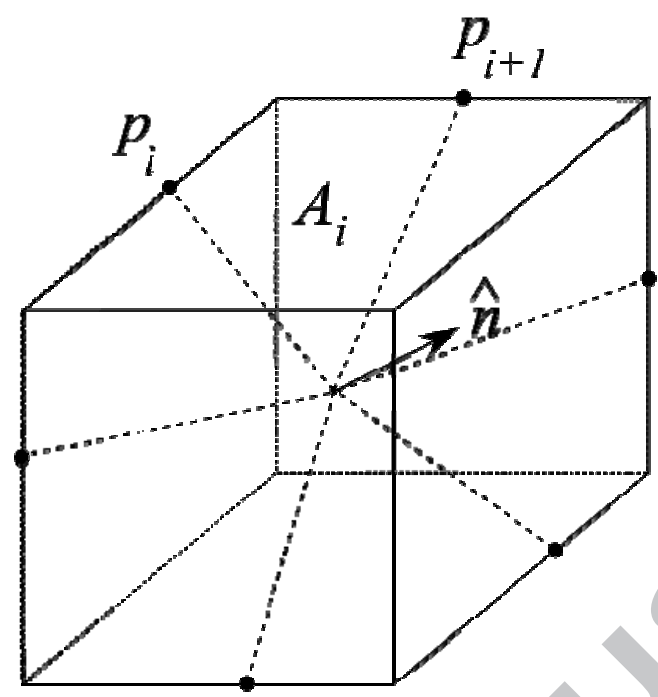

Fig. 6. Calculation of the characteristic length

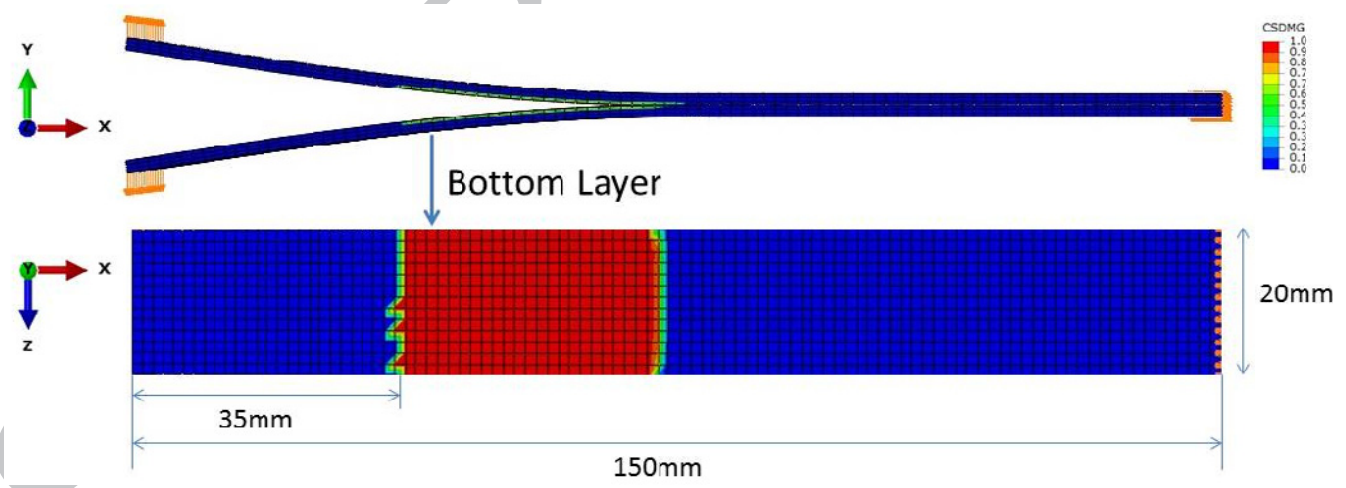

(A)

Page 37 of 53 


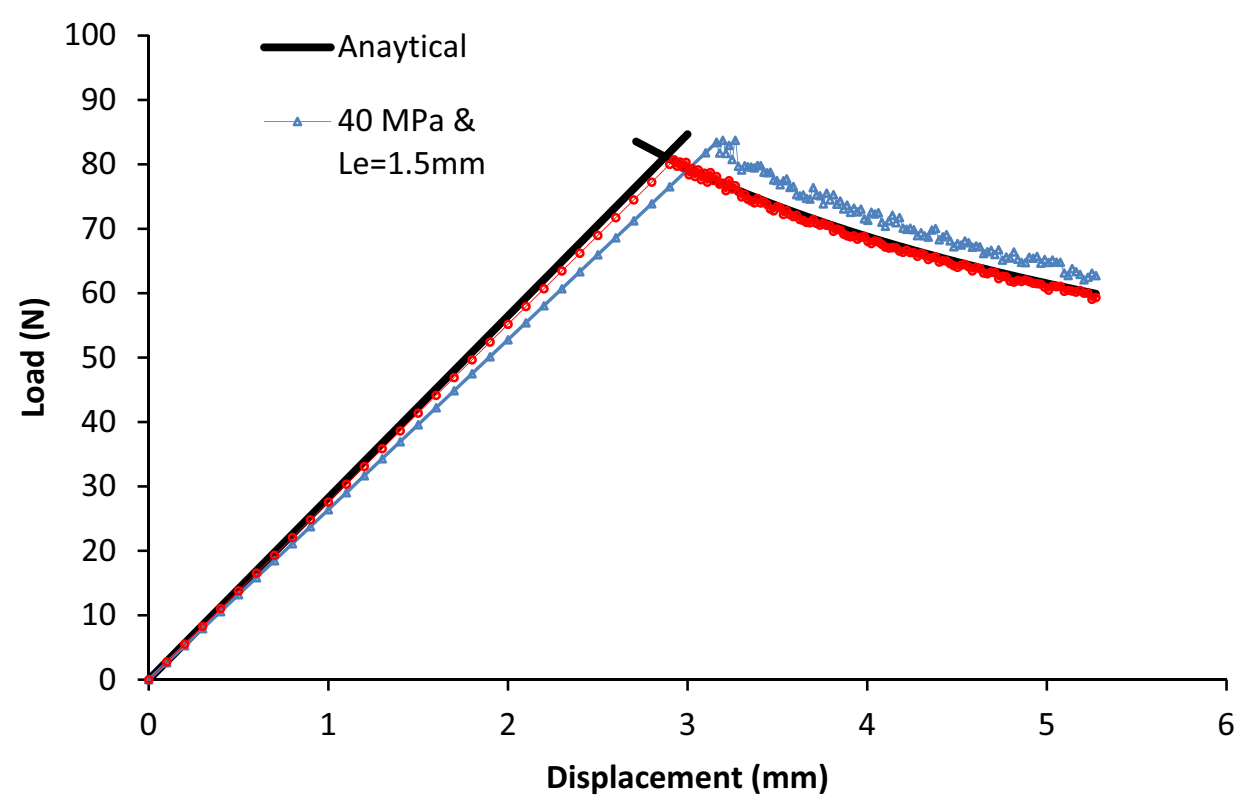

(B)

Fig. 7. (A)DCB simulation with mesh size of $1.5 \mathrm{~mm}$ (B) Load-displacement curve for different mesh densities

Page 38 of 53 


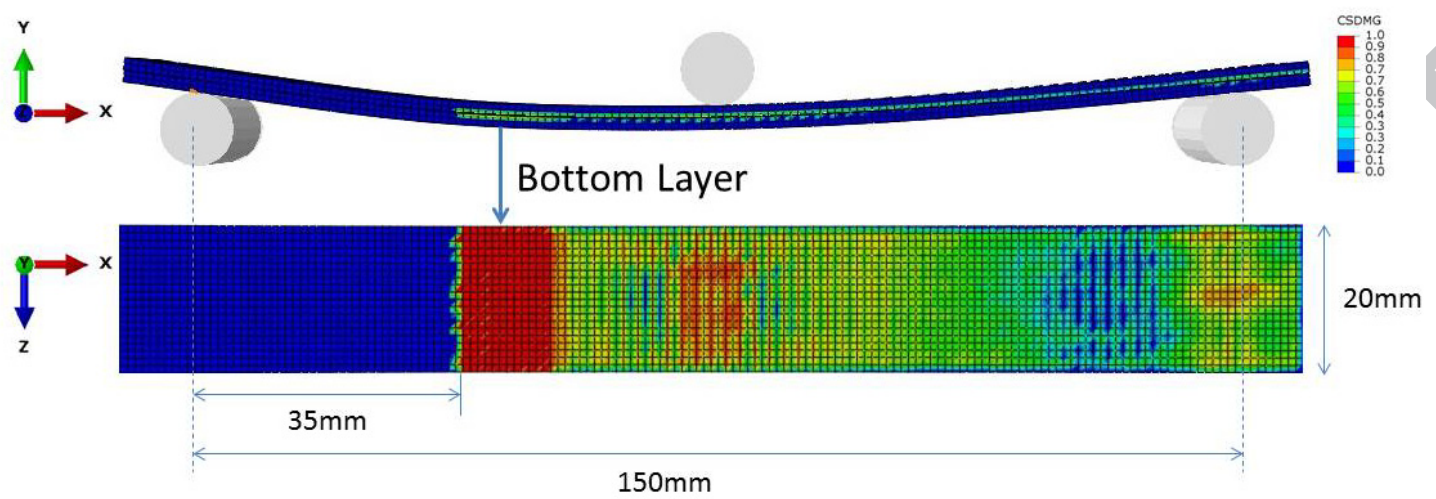

(A)

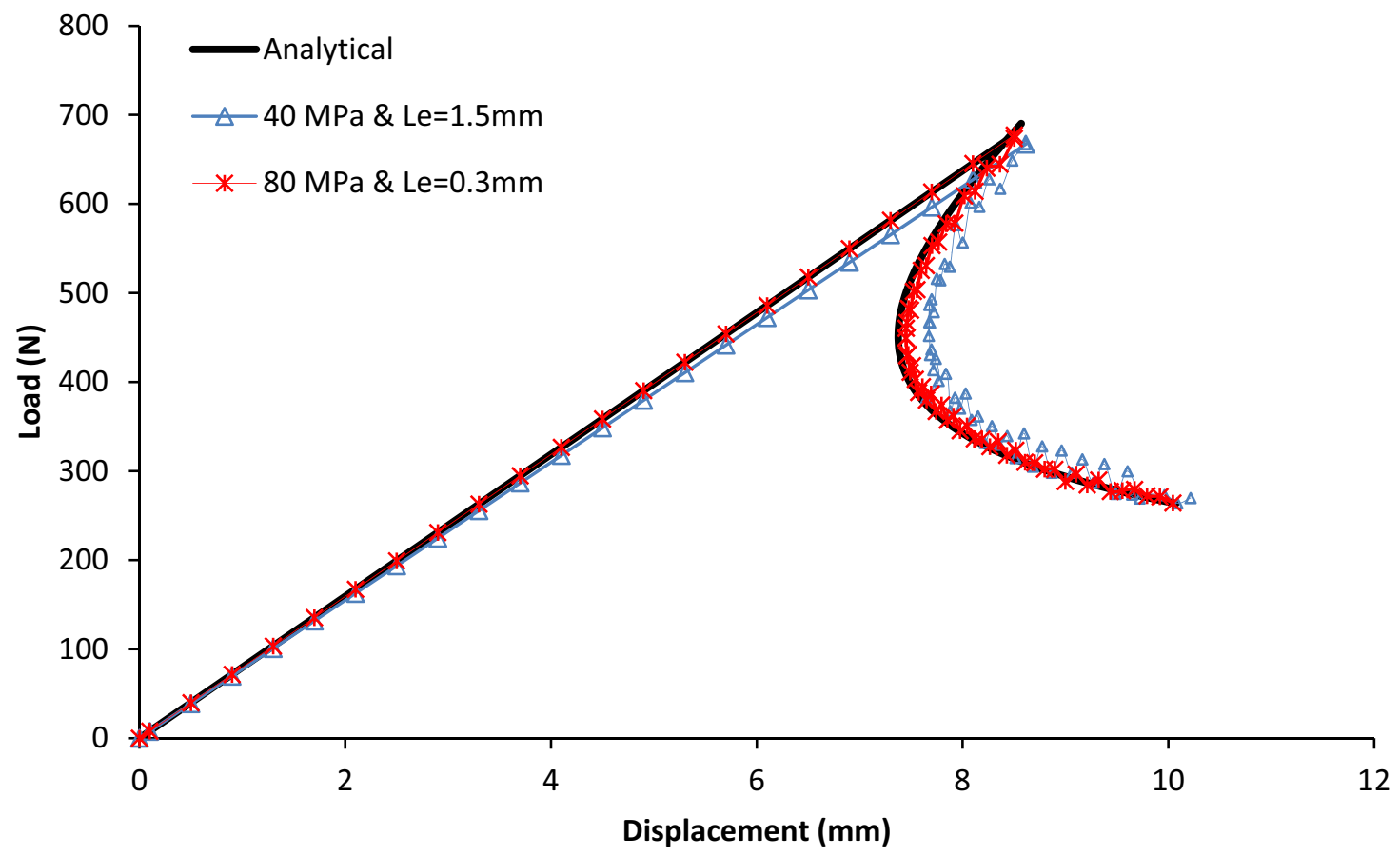

(B)

Fig. 8. (A)ENF simulation with mesh size of 1.5mm (B) Load-displacement curve for different mesh densities

Page 39 of 53 

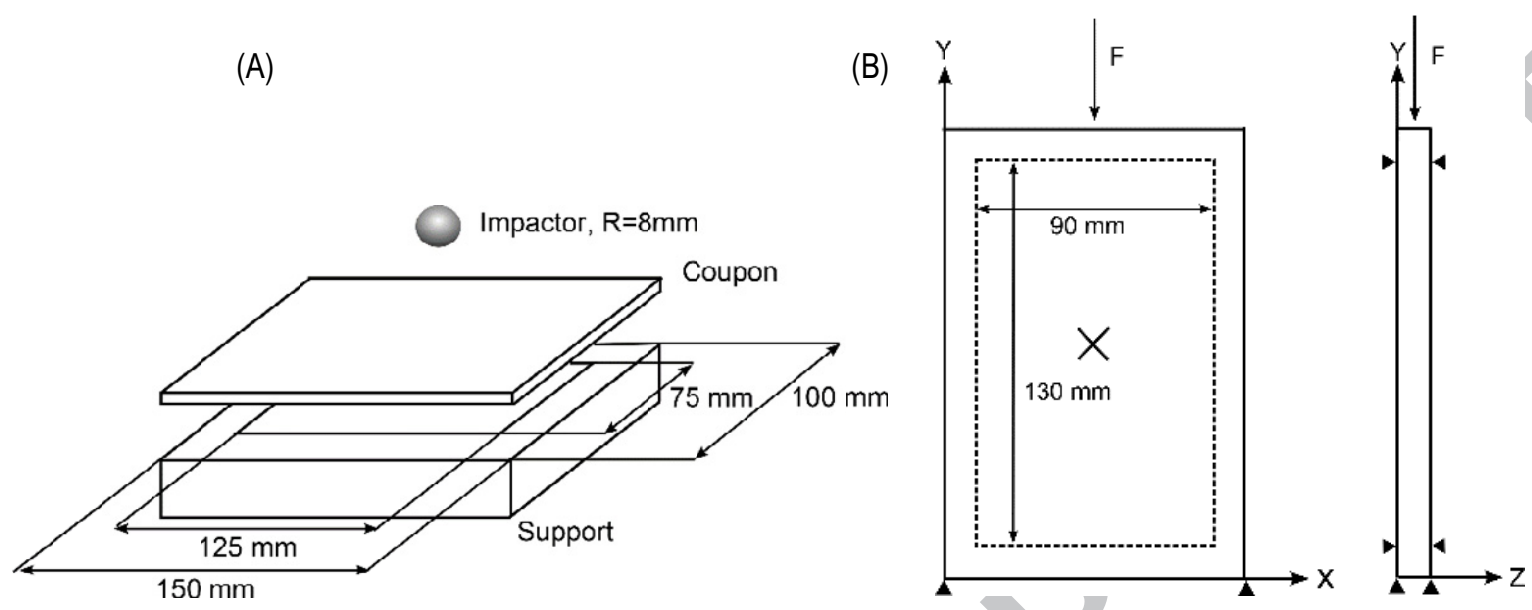

Fig. 9. (A) Impact and (B) CAl test setup

Page 40 of 53 


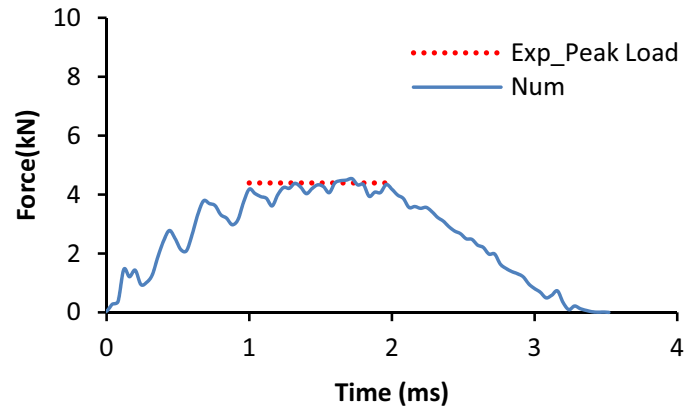

(A)

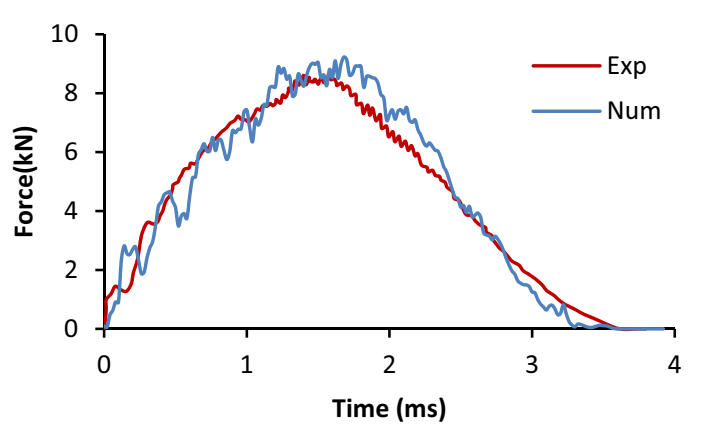

(C)

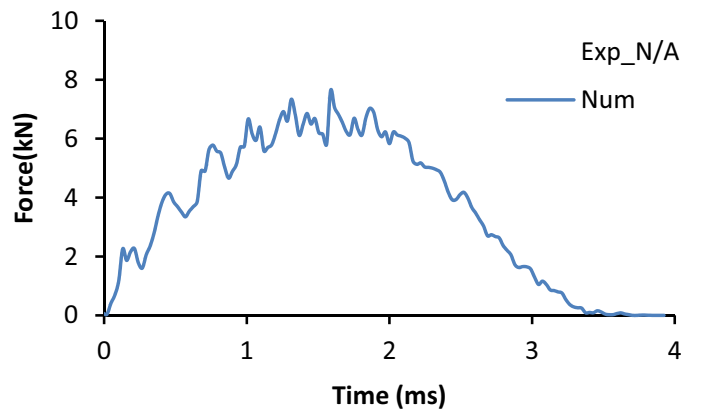

(B)

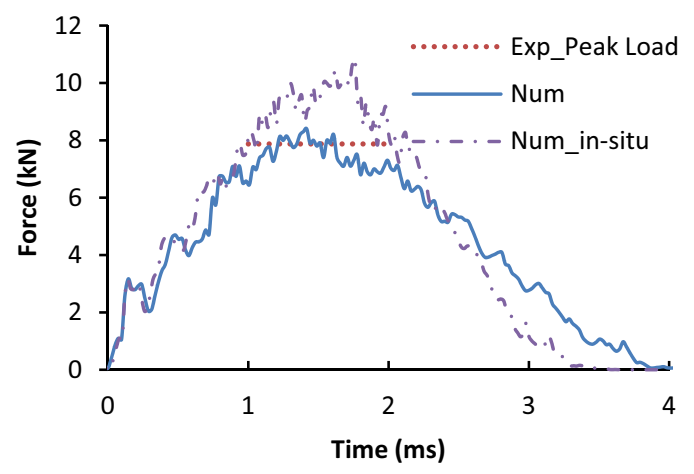

(D)

Fig. 10. Impact force-time curves (A) $6.5 \mathrm{~J}$ (B) $17 \mathrm{~J}$ (C) $25 \mathrm{~J}$ (D) 29.5J 


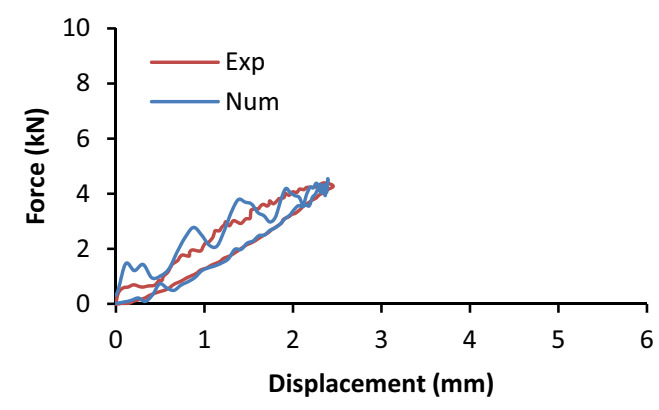

(A)

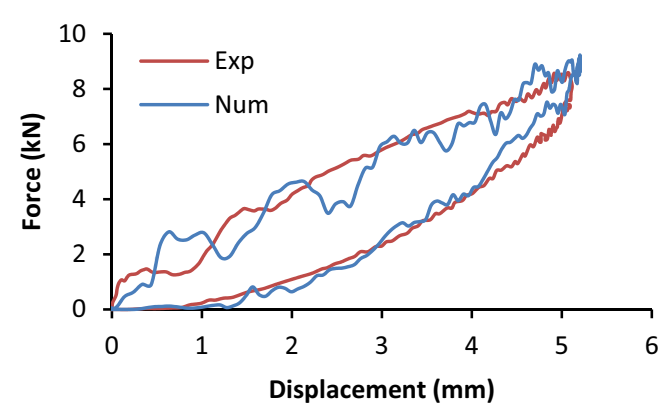

(C)

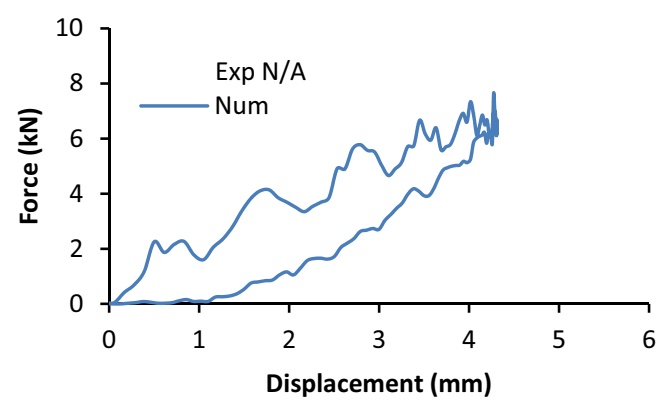

(B)

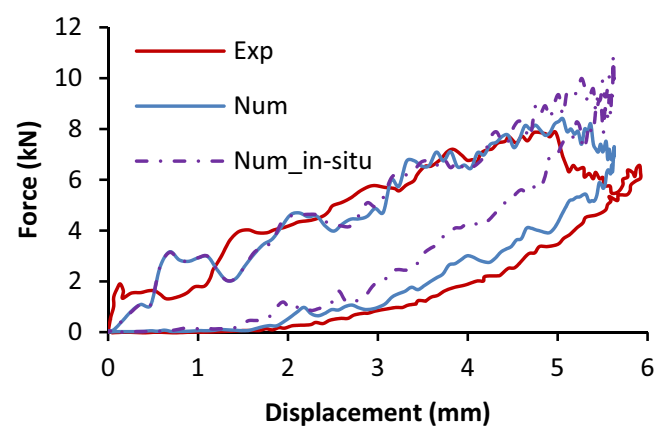

(D)
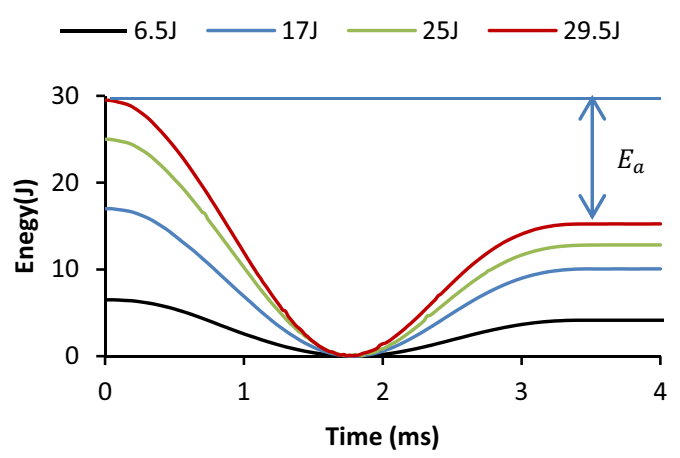

(E)

Fig. 11. Impact force-displacement curves (A) 6.5J (B) 17J (C) 25J (D) 29.5J (E) energy-time curve 


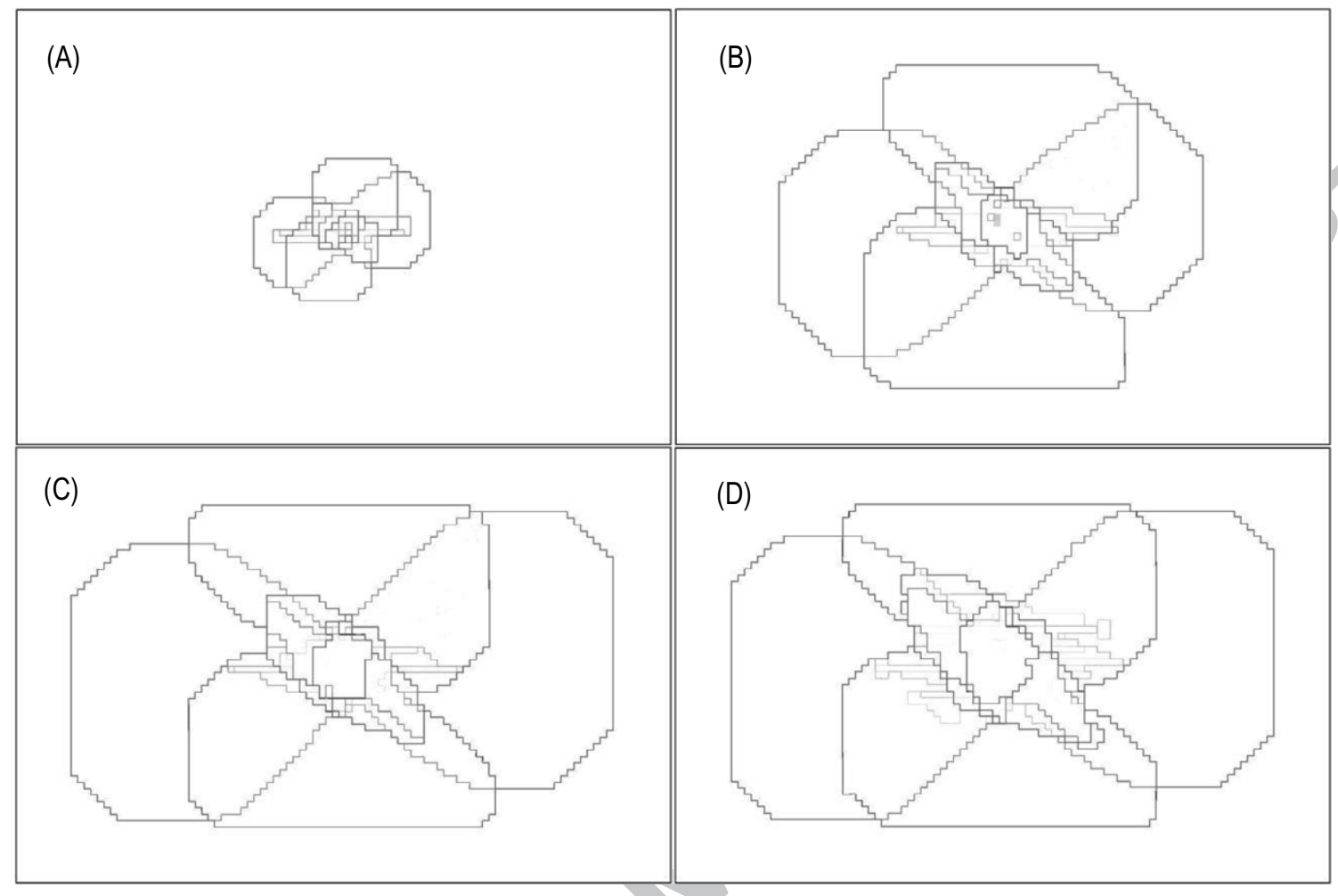

Fig. 12. Intralaminar matrix impact damage envelopes (A) $6.5 \mathrm{~J}$ (B) 17J (C) 25J (D) 29.5J 


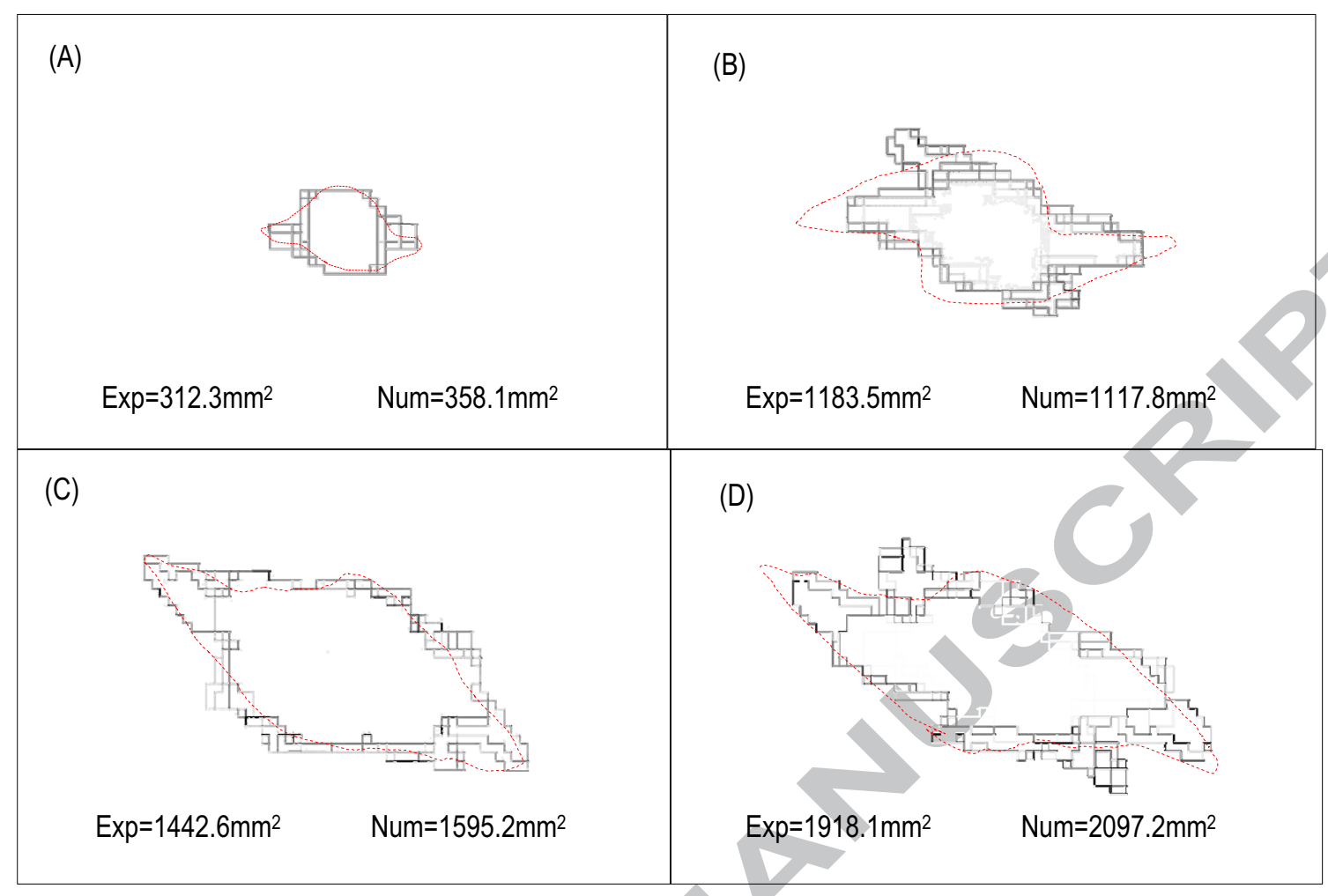

Fig. 13. Delamination damage envelope compared with experimental C-scan outlines (dashed lines)

(A) $6.5 \mathrm{~J}(\mathrm{~B}) 17 \mathrm{~J}(\mathrm{C}) 25 \mathrm{~J}(\mathrm{D}) 29.5 \mathrm{~J}$

Page 44 of 53 


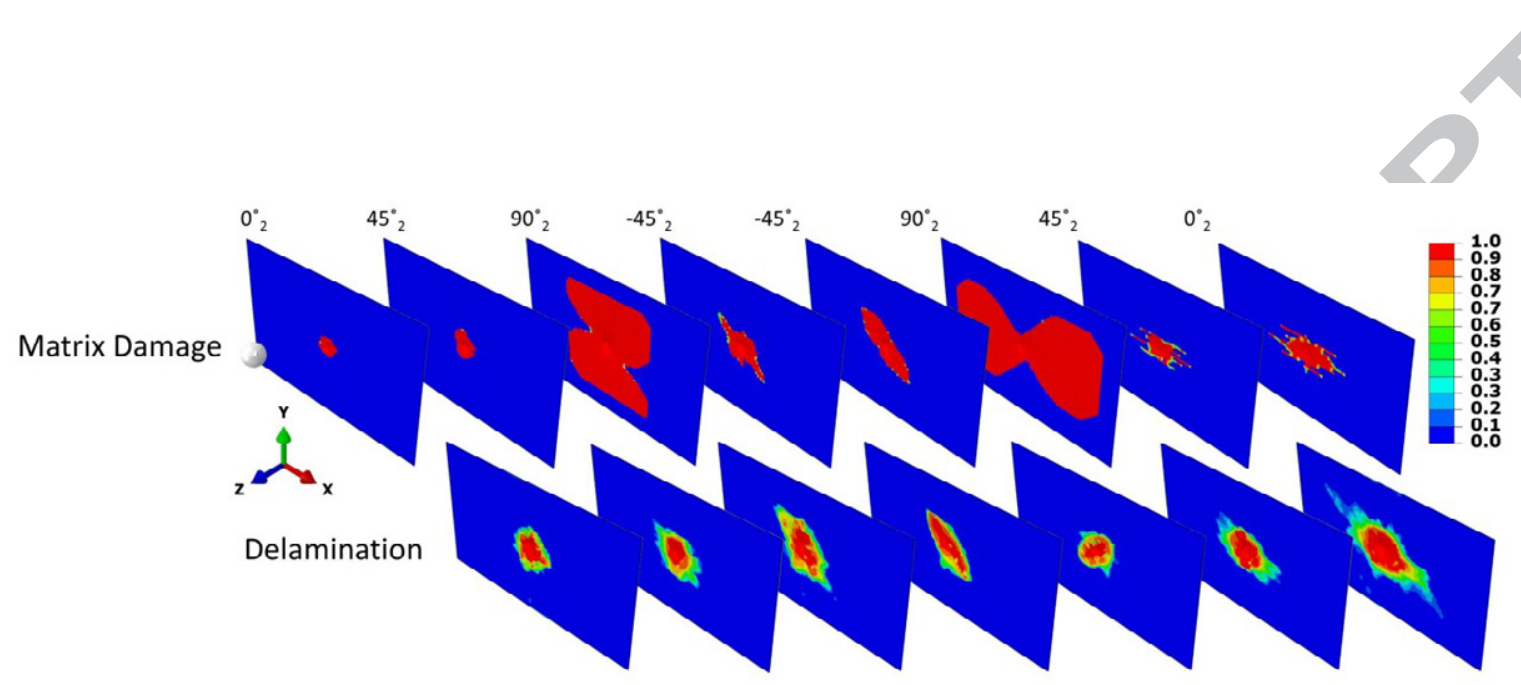

(A)

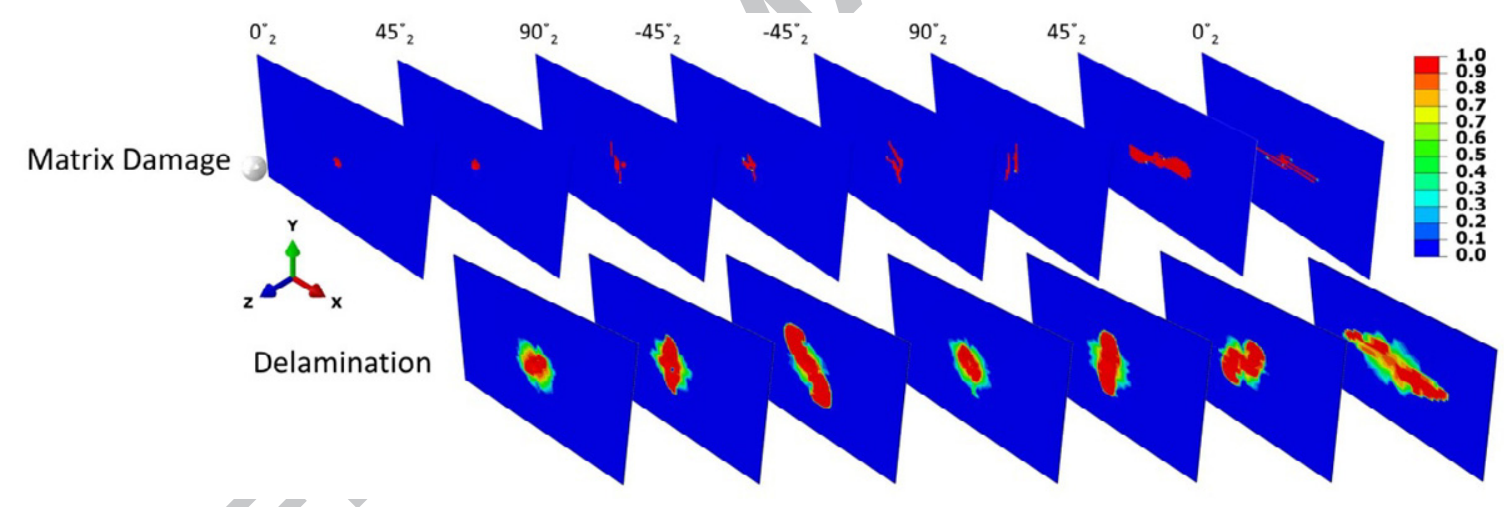

(B)

Fig. 14. Damage contours for plate impacted with $29.5 \mathrm{~J}(\mathrm{~A})$ Standard strength values of a ply (B) Insitu strength values 


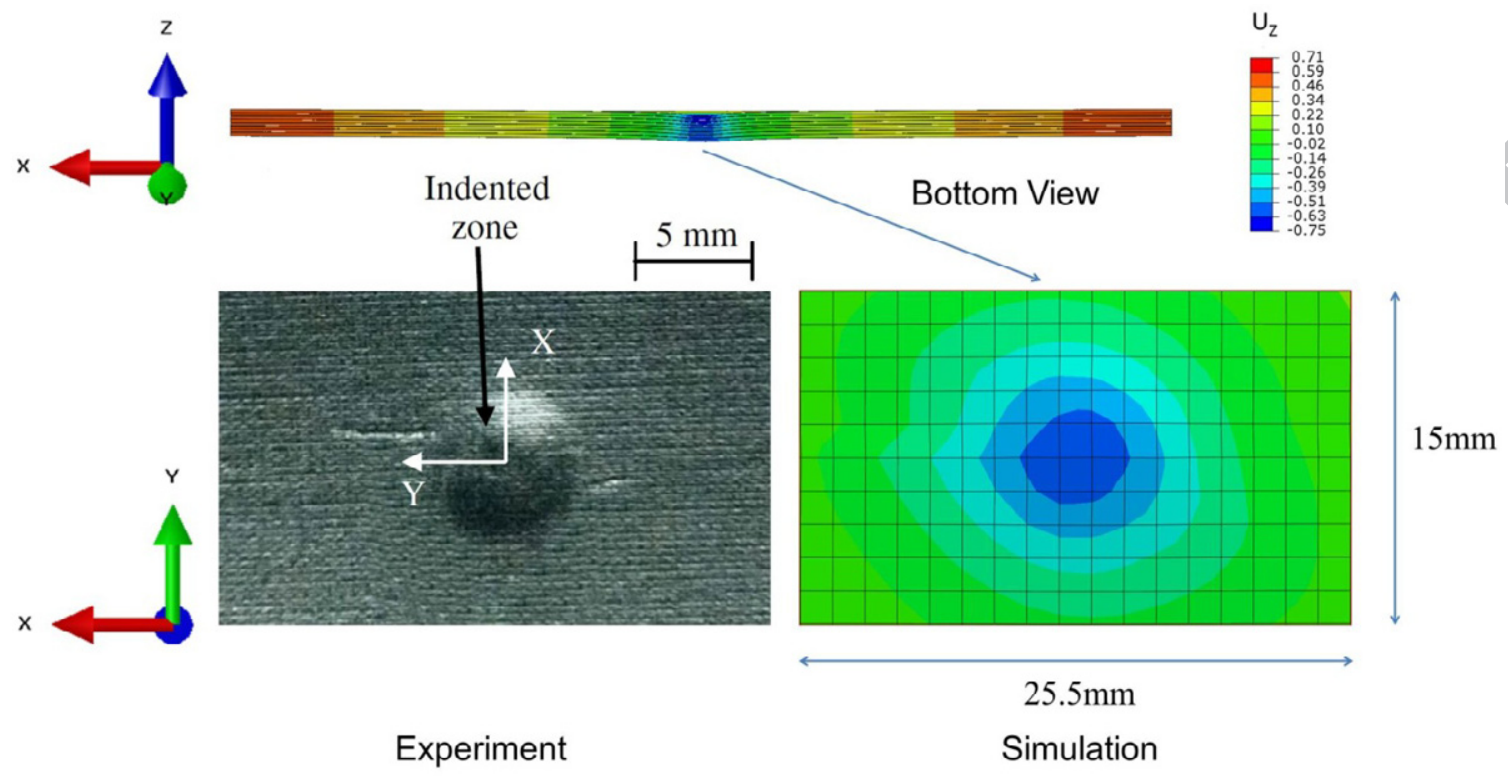

(A)

(B)

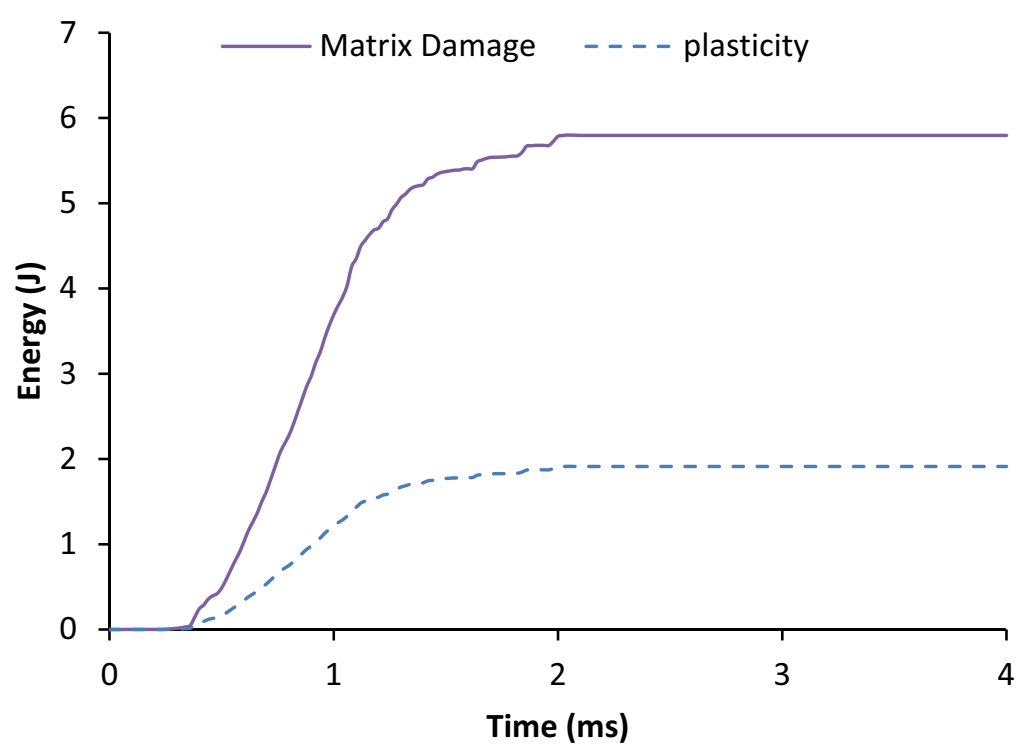

(C)

Fig. 15. Permanent indentation after impact (A) Experimental results $(-0.7 \mathrm{~mm})[20]$; (B) Numerical results; (C) Energy dissipated by plasticity

Page 46 of 53 


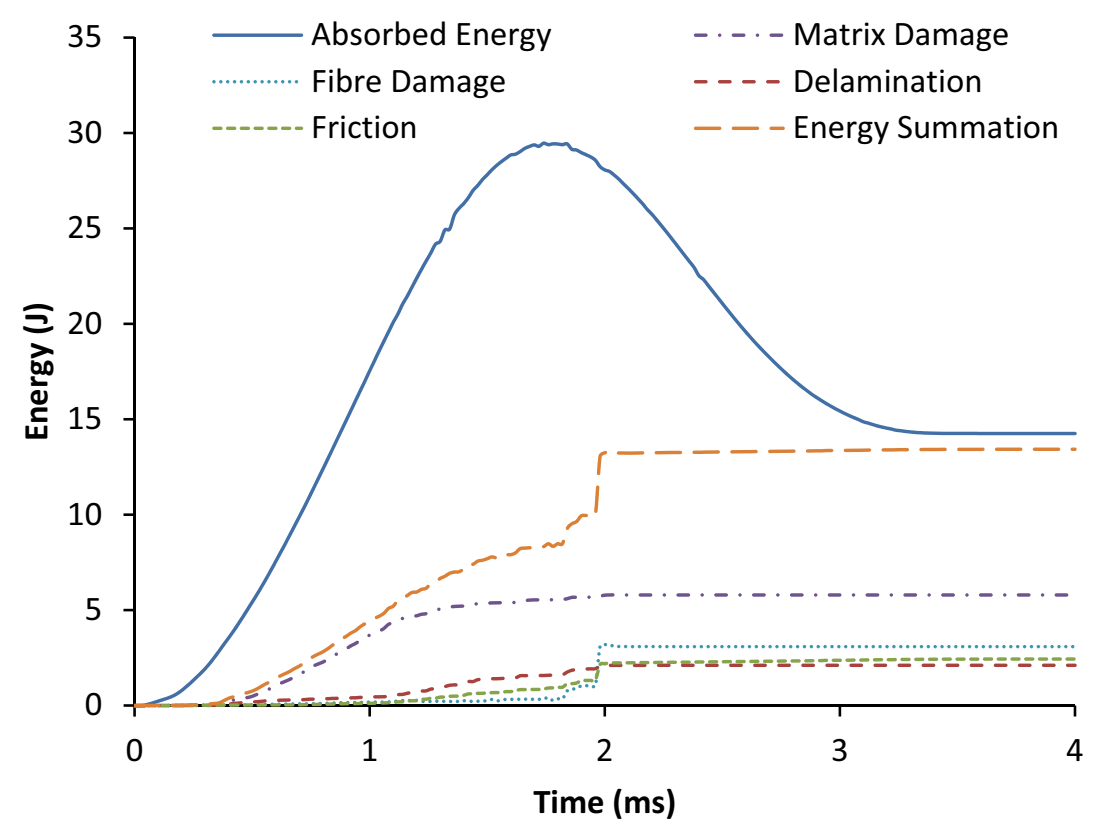

(A)

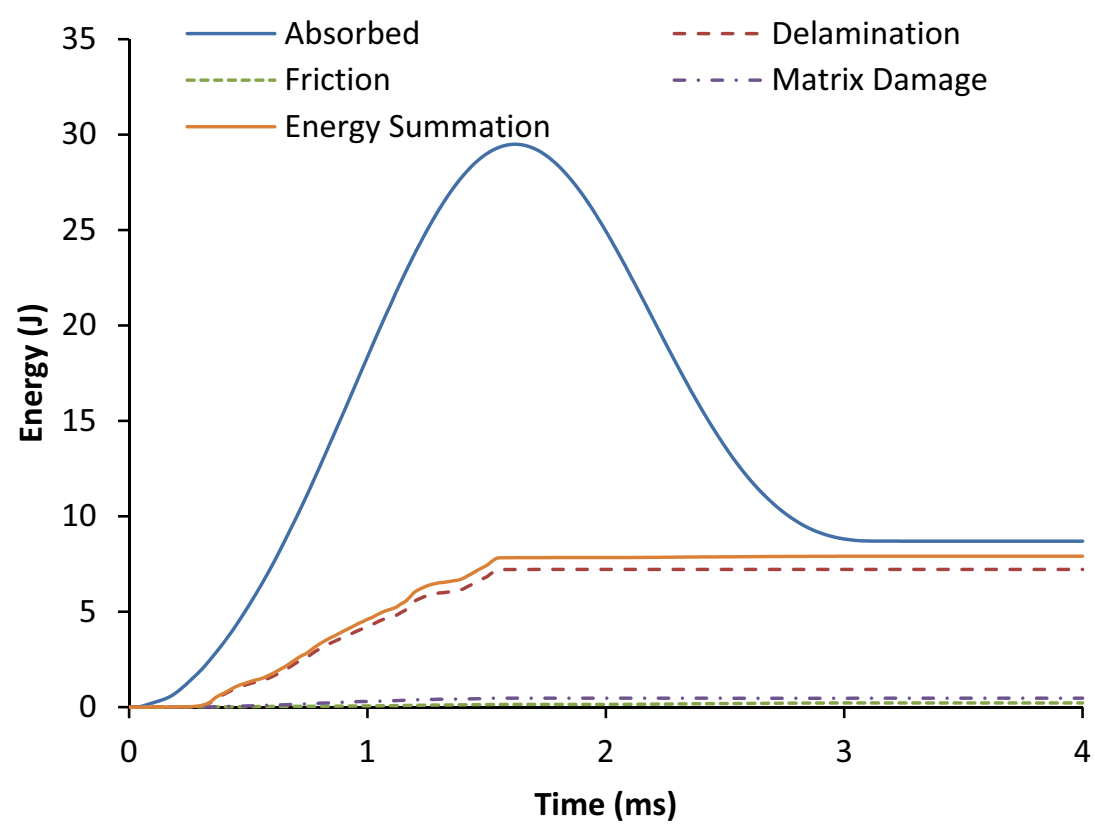

(B)

Fig. 16. Overall damage dissipation mechanism for 29.5J impact (A) Standard strength values of a ply (B) In-situ strength values

Page 47 of 53 


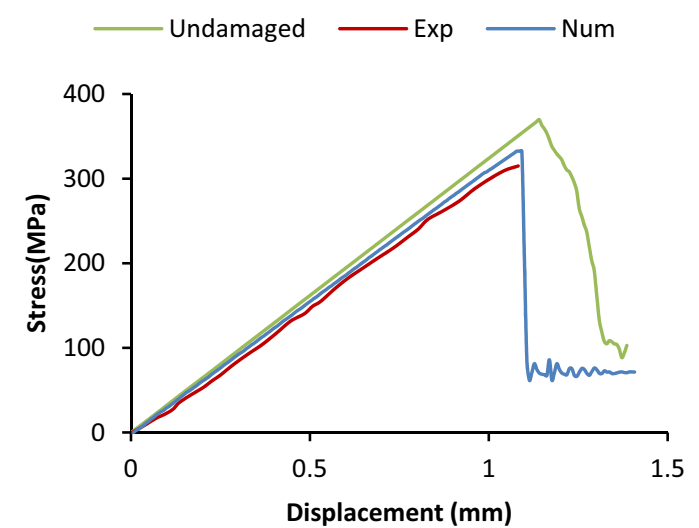

(A)

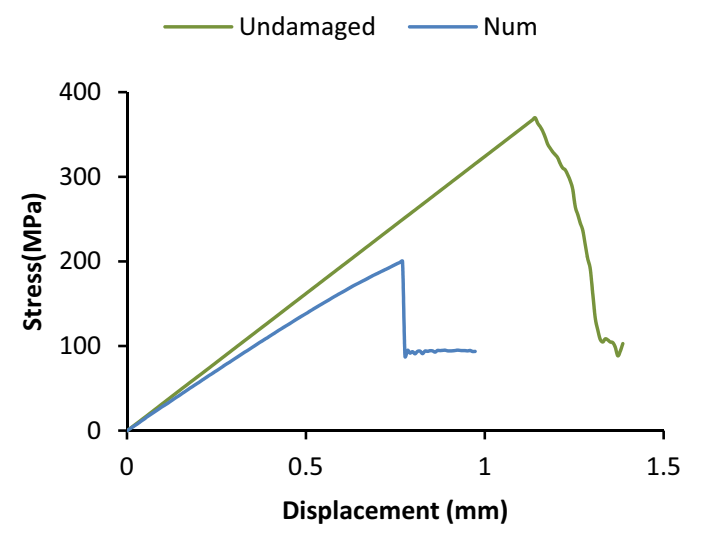

(C)

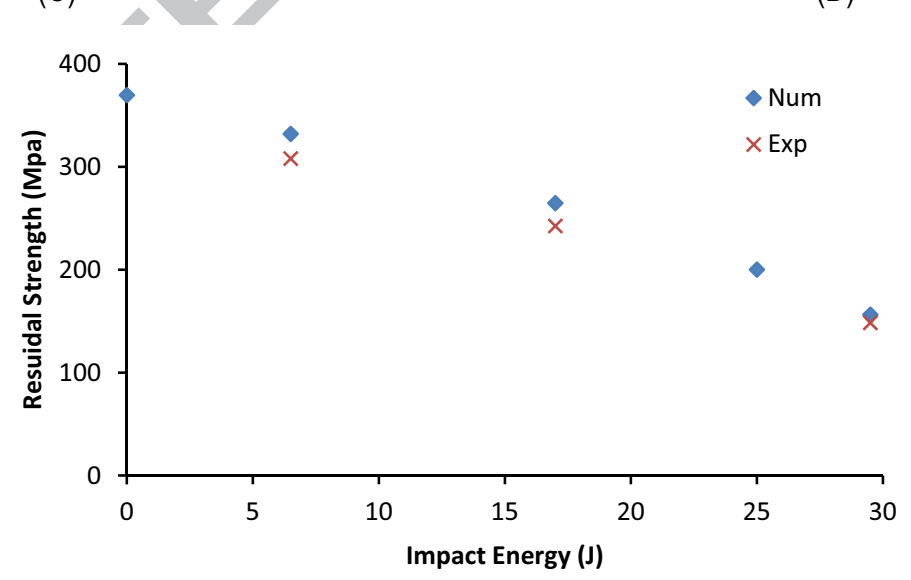

(E)

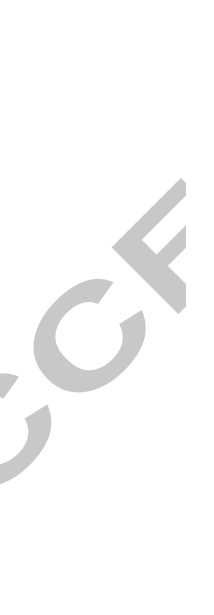

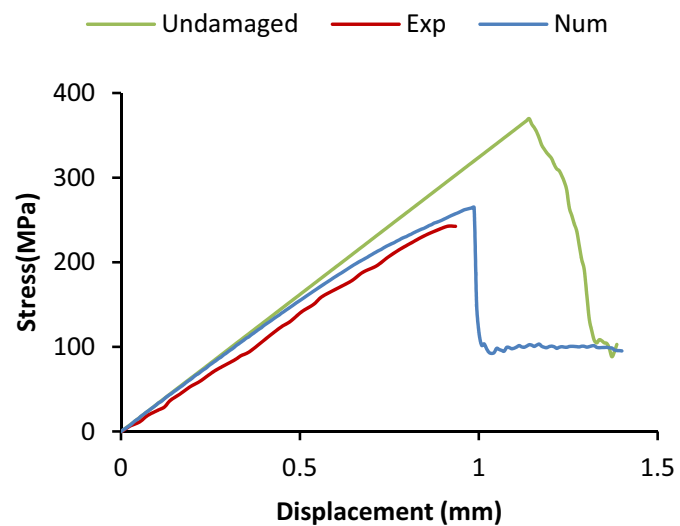

(B)

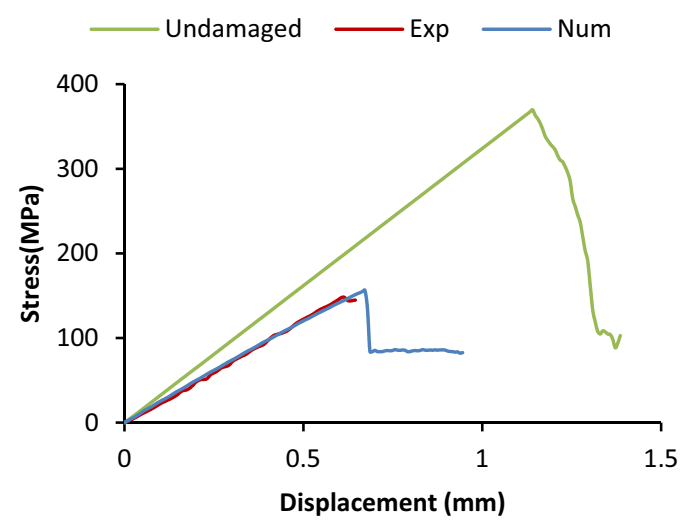

(D)

Fig. 17. CAI stress-displacement curves (A) 6.5J (B) 17J (C) 25J (D) 29.5J (E) CAl strength versus impact energy

Page 48 of 53 


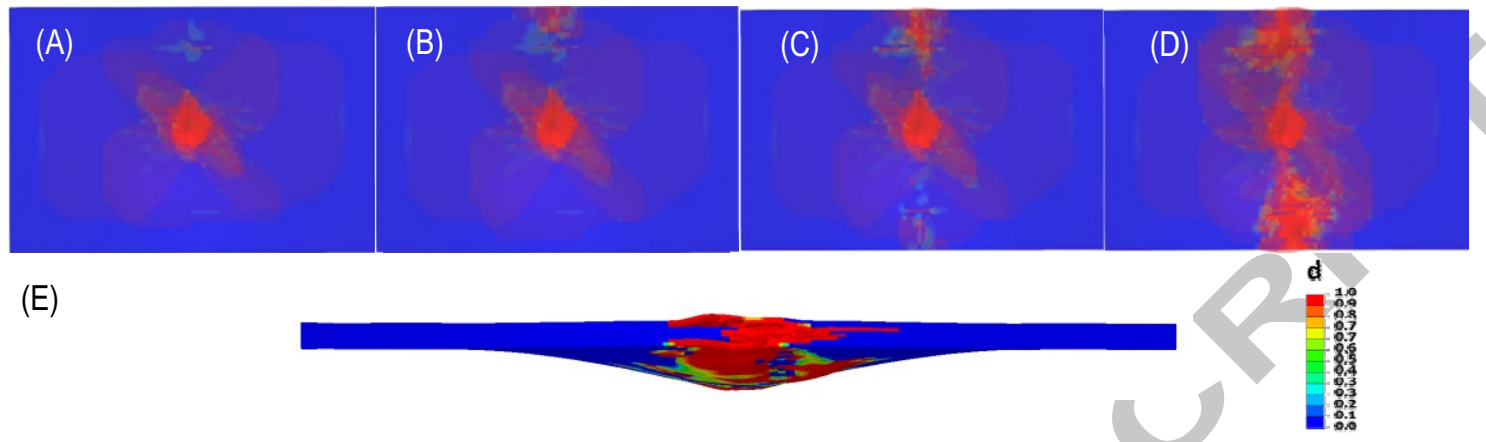

Fig. 18. CAI matrix damage of $29.5 \mathrm{~J}$ impact case at displacement of $(A) 0.6 \mathrm{~mm}(B) 0.65 \mathrm{~mm}$ (C) $0.70 \mathrm{~mm}(\mathrm{D}) 0.75 \mathrm{~mm}$ (E) Side View

Page 49 of 53 


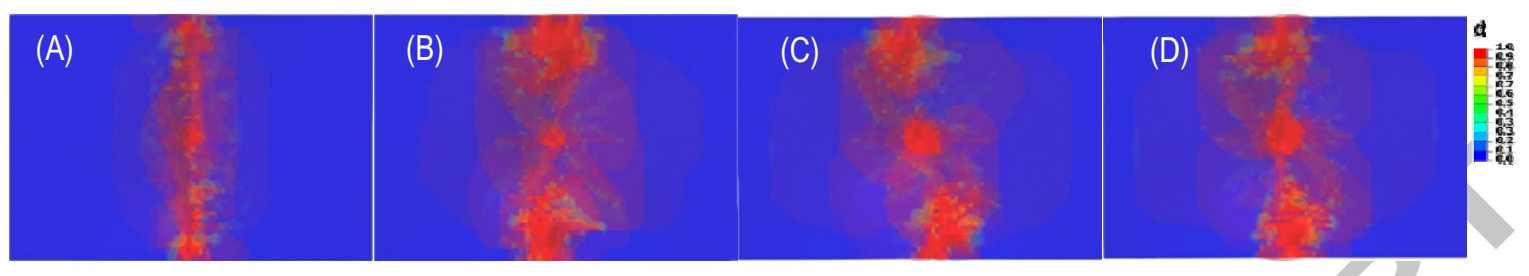

Fig. 19. CAl matrix-dominated damage (A) $6.5 \mathrm{~J}(\mathrm{~B}) 17 \mathrm{~J}(\mathrm{C}) 25 \mathrm{~J}(\mathrm{D}) 29.5 \mathrm{~J}$

Page 50 of 53 


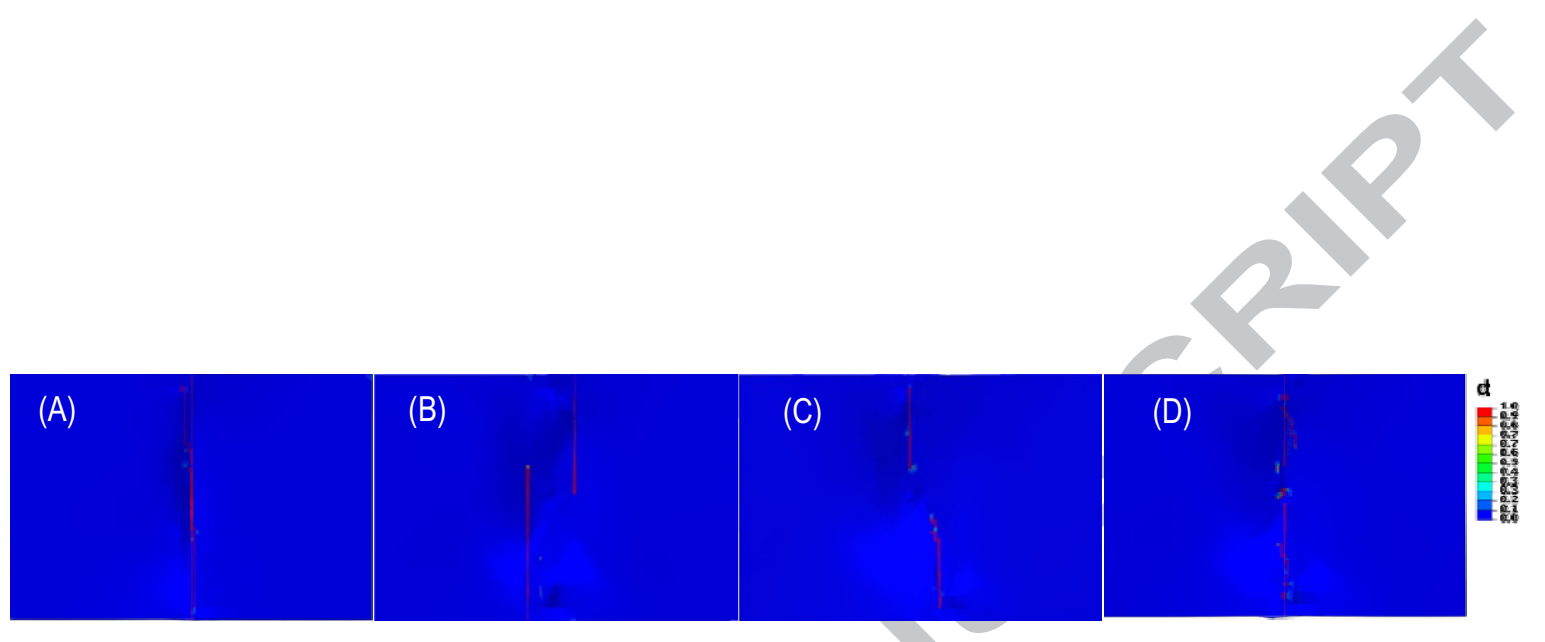

Fig. 20. Fibre failure (A) $6.5 \mathrm{~J}$ (B) $17 \mathrm{~J}$ (C) $25 \mathrm{~J}$ (D) 29.5J

Page 51 of 53 


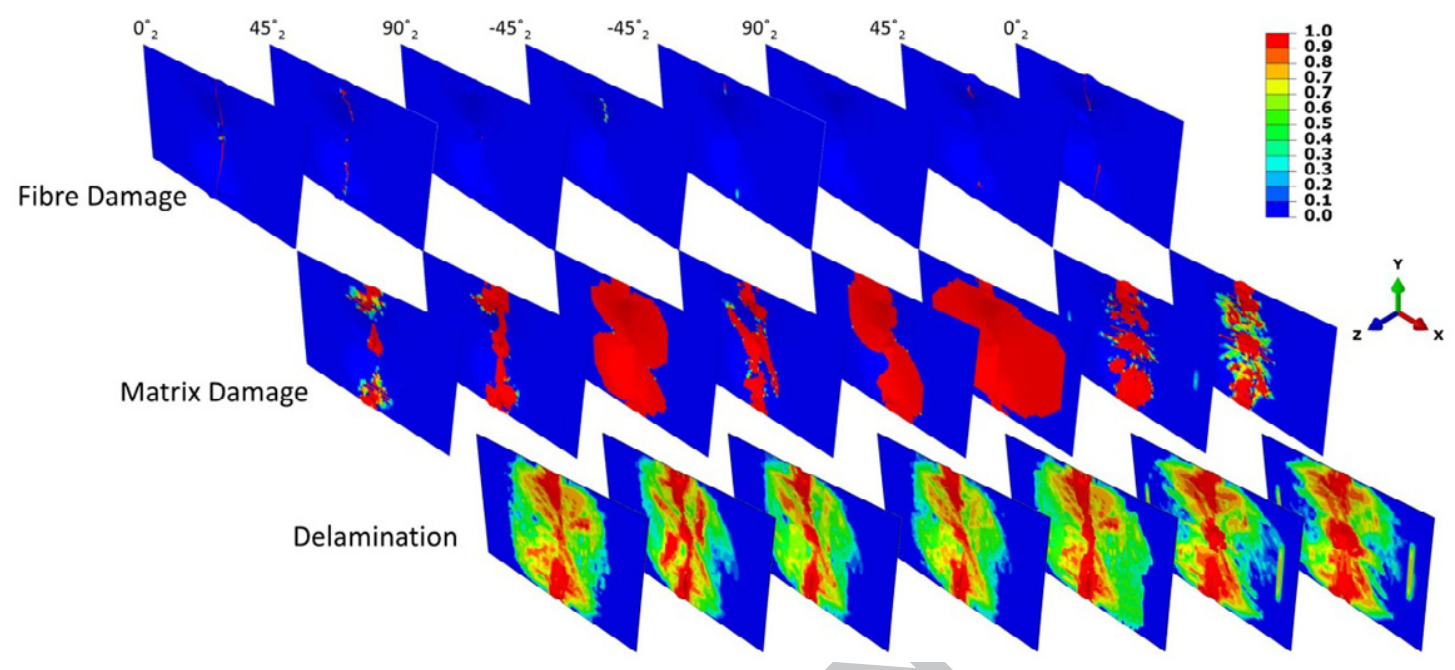

Fig. 21. CAl damage contours for $29.5 \mathrm{~J}$ impact case

Page 52 of 53 


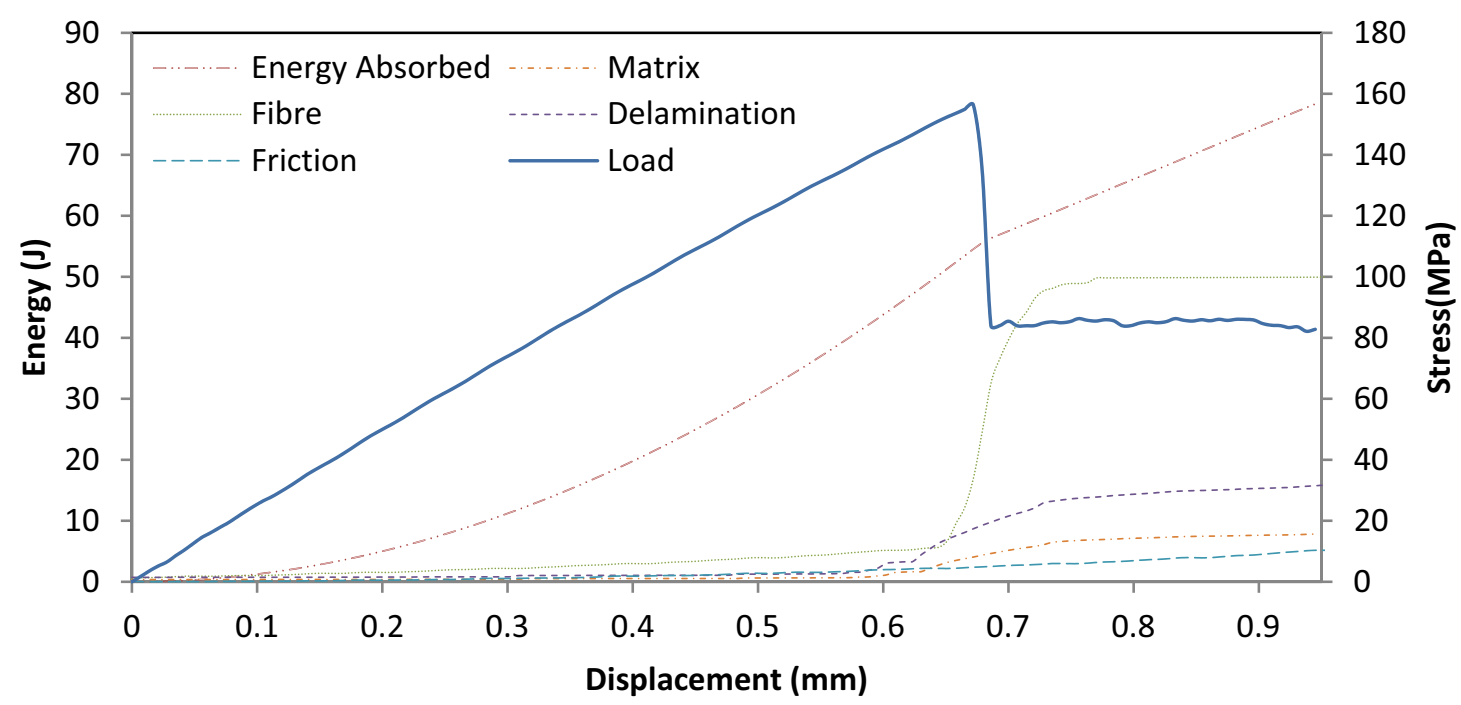

Fig. 22. CAl energy dissipation curves for $29.5 \mathrm{~J}$ impact case 